\title{
EOQ Model for Deteriorating Items with Stock-Level-Dependent Demand Rate and Order-Quantity-Dependent Trade Credit
}

\author{
Jie Min, ${ }^{1}$ Jian Ou, ${ }^{1}$ Yuan-Guang Zhong, ${ }^{2}$ and Xin-Bao Liu ${ }^{3}$ \\ ${ }^{1}$ School of Mathematics and Physics, Anhui Jianzhu University, Hefei 230601, China \\ ${ }^{2}$ School of Business Administration, South China University of Technology, Guangzhou 510640, China \\ ${ }^{3}$ School of Management, Hefei University of Technology, Hefei 230009, China \\ Correspondence should be addressed to Jie Min; minjie@ahjzu.edu.cn
}

Received 24 July 2014; Accepted 29 October 2014; Published 16 December 2014

Academic Editor: Zhen-Lai Han

Copyright (C) 2014 Jie Min et al. This is an open access article distributed under the Creative Commons Attribution License, which permits unrestricted use, distribution, and reproduction in any medium, provided the original work is properly cited.

\begin{abstract}
This paper develops a generalized inventory model for exponentially deteriorating items with current-stock-dependent demand rate and permissible delay in payments. In the model, the payment for the item must be made immediately if the order quantity is less than the predetermined quantity; otherwise, a fixed trade credit period is permitted. The maximization of the average profit per unit of time is taken as the inventory system's objective. The necessary and sufficient conditions and some properties of the optimal solution to the model are developed. Simple solution procedures are proposed to efficiently determine the optimal ordering policies of the considered problem. Numerical example is also presented to illustrate the solution procedures obtained.
\end{abstract}

\section{Introduction}

In classical inventory models, the demand rate of items was often assumed to be either constant or time dependent. However, many marketing researchers and practitioners have recognized that the demand rate of many retail items is usually influenced by the amount of inventory displayed. For example, Whitin [1] stated, "For retail stores the inventory control problem for style goods is further complicated by the fact that inventory and sales are not independent of one another. An increase in inventories may bring about increased sales of some items." Levin et al. [2] and Sliver and Peterson [3] also observed that sales at the retail level tend to be proportional to the inventory displayed and that large piles of goods displayed in a supermarket will lead customers to buy more. The reason behind this phenomenon is a typical psychology of customers. They may have the feeling of obtaining a wide range for selection when a large amount is stored or displayed. Conversely, they may have doubt about the freshness or quality of the product when a small amount is stored. Based on the observed phenomenon, it is clear that in real life the demand rate of items may be influenced by the stock levels. Many researchers have developed lots of inventory models to cover this phenomenon. Gupta and Vrat [4] were the first to develop an inventory model with the initial-stock-dependent consumption rate. Padmanabhan and Vrat [5] proposed an EOQ model for initial-stock-dependent demand and exponential decay items. Giri et al. [6] presented a model under inflation for initial-stock-dependent consumption rate and exponential decay. In addition, Baker and Urban [7] investigated another kind of inventory model in which the demand of item is a polynomial function of the instantaneous stock level. Mandal and Phaujdar [8] developed an inventory model for deteriorating items with linearly current-stock-dependent demand. Pal et al. [9] extended the model of Baker and Urban [7] to the case of deteriorating items. Padmanabhan and Vrat [10] further developed three models for deteriorating items under current-stock-level-dependent demand rate: without backorder, with complete backorder, and with partial backorder. Chung et al. [11] modified Padmanabhan and Vrat's [10] models by showing the necessary and sufficient conditions of the existing optimal solution for models with no backorder and complete backorder. Zhou and Yang [12] developed 
an inventory model for a general inventory-level-dependent demand with limited storage space. Moreover, many further extensive models were developed by researchers such as Balkhi and Benkherouf [13], Dye and Ouyang [14], Zhou and Yang [15], Wu et al. [16], and Alfares [17].

In all the above inventory models with stock-leveldependent demand rate assumed that the retailer must pay for the items as soon as the items are received. However, in the real life, the supplier sometimes will offer the retailer a delay period, that is, a trade credit period, in paying for the amount of purchasing cost. Before the end of the trade credit period, the retailer can sell the goods and accumulate the revenue to earn interest. A higher interest is charged if the payment is not settled by the end of trade credit period. In real world, the supplier often makes use of this policy to promote their commodities. During the recent two decades, the effect of a permissible delay in payments on the optimal inventory systems has received more attention from numerous researchers. Goyal [18] explored a single item EOQ model under permissible delay in payments. Aggarwal and Jaggi [19] extended Goyal's [18] model to the case with deteriorating items. Jamal et al. [20] further generalized the above inventory models to allow for shortages. Other related articles can be found in Sarker et al. [21], Teng [22], Huang [23], Chang et al. [24, 25], Chung and Liao [26], Teng et al. [27], Liao [28] and Teng and Goyal [29], and their references. More recently, Chen et al. [30] studied an economic order quantity model under conditionally permissible delay in payments, in which the supplier offers the retailer a fully permissible delay periods if the retailer orders more than or equal to a predetermined quantity, otherwise partial payments will be provided. Chang et al. [31] developed an appropriate inventory model for noninstantaneously deteriorating items where suppliers provide a permissible payment delay schedule linked to order quantity. However, all of the abovementioned papers with trade credit financing did not address inventory-level-dependent demand rate.

The present paper establishes an EOQ model for deteriorating items with current-inventory-level-dependent demand rate and permissible delay in payments which is dependent on the retailer's order quantity. That is, if the order quantity is less than the predetermined quantity, the payment for the item must be made immediately; otherwise, a fixed trade credit period is permitted. We then establish the proper mathematical model and study the necessary and sufficient conditions of the optimal solution to the model. Some properties of the optimal solution to the model are proposed for obtaining the optimal replenishment quantity and replenishment cycle, which make the average profit of the system maximized.

The remainder of the paper is organized as below. The next section introduces some notations and assumptions used in this paper. We then present in Section 3 the formulation of the inventory model with current-stock-leveldependent demand rate and order-quantity-dependent trade credit. Section 4 examines the existence and uniqueness of the optimal solution to the considered inventory system and shows some properties of the optimal ordering policies. In Section 5, numerical example is given to illustrate the solution procedure obtained in this paper. Some conclusions are included in Section 6.

\section{Notations and Assumptions}

The following notations and assumptions are used in the paper.

\section{Notations}

$K$ : ordering cost one order in dollars,

$c$ : purchase cost per unit in dollars,

$s$ : selling price per unit in dollars $(s>c)$,

$h$ : stock holding cost per year per unit in dollars (excluding interest charges),

$\theta$ : deteriorating rate of items $(0<\theta<1)$,

$Q_{d}$ : the qualified quantity in units at or beyond which the delay in payments is permitted,

$T_{d}$ : the time interval in years in which $Q_{d}$ units are depleted to zero due to both demand and deterioration,

$I_{e}$ : interest which can be earned per $\$$ per year by the retailer,

$I_{p}$ : interest charges per $\$$ in stocks per year by the supplier,

$M$ : the retailer's trade credit period offered by supplier in years,

$T$ : inventory cycle length in years (decision variable),

$Q$ : the retailer's order quantity in units per cycle,

$\Pi(T)$ : the retailer's average profit function per unit time in dollars.

\section{Assumptions}

(1) The demand rate $R(t)$ is a known function of retailer's instantaneous stock level $I(t)$, which is given by

$$
R(t)=D+\alpha I(t)
$$

where $D$ and $\alpha$ are positive constants.

(2) The time horizon of the inventory system is infinite.

(3) The lead time is negligible.

(4) Shortages are not allowed to occur.

(5) When the order quantity is less than the qualified quantity $Q_{d}$, the payment for the item must be made immediately. Otherwise, the fixed trade credit period $M$ is permitted.

(6) If the trade credit period $M$ is offered, the retailer would settle the account at $t=M$ and pay for the interest charges on items in stock with rate $I_{p}$ over the interval $[M, T]$ as $T \geq M$, whereas the retailer settles the account at $t=M$ and does not need to pay any interest charge of items in stock during the whole cycle as $T \leq M$. 
(7) The retailer can accumulate revenue and earn interest from the very beginning of inventory cycle until the end of the trade credit period offered by the supplier. That is, the retailer can accumulate revenue and earn interest during the period from $t=0$ to $t=M$ with rate $I_{e}$ under the condition of trade credit.

(8) $s \geq c, I_{p} \geq I_{e}$, which are reasonable assumptions in reality.

\section{Mathematical Formulation of the Model}

Based on the above assumptions, the considered inventory system goes like this: at the beginning (say, the time $t=0$ ) of each replenishment cycle, items of $Q$ units are held, and the items are depleted gradually in the interval $[0, T]$ due to the combined effects of demand and deterioration. At time $t=T$, the inventory level reaches zero, and the whole process is repeated.

The variation of inventory level, $I(t)$, with respect to time can be described by the following differential equation:

$$
\frac{d I(t)}{d t}=-D-\alpha I(t)-\theta I(t), \quad 0 \leq t \leq T
$$

with the boundary condition $I(T)=0$.

The solution to the above differential equation is

$$
I(t)=\frac{D}{\alpha+\theta}\left(e^{(\alpha+\theta)(T-t)}-1\right), \quad 0 \leq t \leq T .
$$

So the retailer's order size per cycle is

$$
Q=I(0)=\frac{D}{\alpha+\theta}\left(e^{(\alpha+\theta) T}-1\right) \text {. }
$$

We observe that if the order quantity $Q<Q_{d}$, then the payment must be made immediately. Otherwise, the retailer will get a certain credit period, $M$. Hence, from (4) one has the fact that the inequality $Q<Q_{d}$ holds if and only if $T<T_{d}$, where $T_{d}$ is given as below:

$$
T_{d}=\frac{1}{\alpha+\theta} \ln \left[1+(\alpha+\theta) \frac{Q_{d}}{D}\right] .
$$

The elements comprising the profit function per cycle of the retailer are listed below.

(a) The ordering cost $=K$.

(b) The holding cost (excluding interest charges) = $h \int_{0}^{T} I(t) d t=\left(h D /(\alpha+\theta)^{2}\right)\left[e^{(\alpha+\theta) T}-(\alpha+\theta) T-1\right]$.

(c) The purchasing cost $=c Q=(c D /(\alpha+\theta))\left[e^{(\alpha+\theta) T}-1\right]$.

(d) The sales revenue $=s \int_{0}^{T} R(t) d t=s[\theta D T /(\alpha+\theta)+$ $\left.\left(\alpha D /(\alpha+\theta)^{2}\right)\left(e^{(\alpha+\theta) T}-1\right)\right]$.

(e) According to the above assumption, there are two cases to occur in interest payable in each order cycle.

Case 1 ( $\left.T \leq T_{d}\right)$. In this case, the delay in payments is not permitted. That is, all products in inventory have to be financed with annual rate $I_{p}$. Therefore, interest payable in each order cycle

$$
=c I_{p} \int_{0}^{T} I(t) d t=\frac{c I_{p} D}{(\alpha+\theta)^{2}}\left[e^{(\alpha+\theta) T}-(\alpha+\theta) T-1\right] .
$$

Case $2\left(T \geq T_{d}\right)$. In this case, the delay credit period $M$ in payments is permitted, which arouses two subcases: Subcase 2.1 where $T \leq M$ and Subcase 2.2 where $T \geq M$.

Subcase $2.1(T \leq M)$. Since the cycle time $T$ is shorter than the credit period $M$, there is no interest paid for financing the inventory in stock. So the interest payable in each order cycle $=0$.

Subcase $2.2(T \geq M)$. When the credit period $M$ is shorter than or equal to the replenishment cycle time $T$, the retailer starts paying the interest for the items in stock after time $M$ with rate $I_{p}$. Hence, the interest payable in each order cycle

$$
\begin{aligned}
& =c I_{p} \int_{M}^{T} I(t) d t \\
& =\frac{c I_{p} D}{(\alpha+\theta)^{2}}\left[e^{(\alpha+\theta)(T-M)}-(\alpha+\theta)(T-M)-1\right] .
\end{aligned}
$$

(f) Similarly, there are also two cases to occur in interest earned in each order cycle.

Case $1\left(T \leq T_{d}\right)$. In this case, the delay in payments is not permitted, so the interest earned in each order cycle $=0$.

Case $2\left(T \geq T_{d}\right)$. In this case, the delay in payments is permitted, which causes two subcases as below.

Subcase $2.1(T \leq M)$. Since the cycle time $T$ is shorter than the credit period $M$, from time 0 to $T$ the retailer sells the goods and continues to accumulate the sales revenue to earn interest $s I_{e} \int_{0}^{T} \int_{0}^{t} R(u) d u d t$, and from time $T$ to $M$ the retailer can use the sales revenue generated in $[0, T]$ to earn interest $s I_{e} \int_{0}^{T} R(u) d u(M-T)$. Therefore, the interest earned from time 0 to $M$ per cycle

$$
\begin{gathered}
=s I_{e}\left[\int_{0}^{T} \int_{0}^{t} R(u) d u d t+\int_{0}^{T} R(u) d u(M-T)\right] \\
=s I_{e}\left\{\frac{\theta D T^{2}}{2(\alpha+\theta)}-\frac{\alpha D}{(\alpha+\theta)^{3}}\left(e^{(\alpha+\theta) T}-1\right)\right. \\
+\frac{\alpha D T}{(\alpha+\theta)^{2}} e^{(\alpha+\theta) T} \\
\left.+\left[\frac{\theta D T}{\alpha+\theta}+\frac{\alpha D}{(\alpha+\theta)^{2}}\left(e^{(\alpha+\theta) T}-1\right)\right](M-T)\right\} .
\end{gathered}
$$

Subcase $2.2(T \geq M)$. In this case, the delay in payments is permitted, and during time 0 through $M$ the retailer sells the goods and continues to accumulate sales revenue and earns 
the interest with rate $I_{e}$. Therefore, the interest earned from time 0 to $M$ per cycle

$$
\begin{aligned}
& =s I_{e} \int_{0}^{M} \int_{0}^{t} R(u) d u d t \\
& =s I_{e}\left[\frac{\theta D M^{2}}{2(\alpha+\theta)}+\frac{\alpha D M}{(\alpha+\theta)^{2}} e^{(\alpha+\theta) T}\right. \\
& \left.\quad+\frac{\alpha D}{(\alpha+\theta)^{3}} e^{(\alpha+\theta) T}\left(e^{-(\alpha+\theta) M}-1\right)\right] .
\end{aligned}
$$

From the above, the profit function for the retailer can be expressed as

$$
\begin{aligned}
& \Pi(T)=\{\text { Sales revenue }+ \text { interest earned }- \text { ordering cost } \\
& \\
&- \text { holding cost }- \text { purchasing cost } \\
&- \text { interest payable }\} \times T^{-1} .
\end{aligned}
$$

On simplification and summation, we get the profit function as the following three forms:

(A) if $T \leq T_{d}$, then

$$
\begin{aligned}
\Pi(T)= & \Pi_{1}(T) \\
=\frac{1}{T} & \left\{\frac{D E}{(\alpha+\theta)^{2}}\left(e^{(\alpha+\theta) T}-1\right)\right. \\
& \left.+\frac{D T}{\alpha+\theta}\left(h+\theta s+c I_{p}\right)-K\right\},
\end{aligned}
$$

(B) if $T>T_{d}$ but $T \leq M$, then

$$
\begin{aligned}
\Pi(T)=\Pi_{2}(T) \\
=\frac{1}{T}\left\{\frac{D F}{(\alpha+\theta)^{2}}\left(e^{(\alpha+\theta) T}-1\right)\right. \\
+\frac{D T}{\alpha+\theta}\left(h+\theta s+\theta s I_{e} M+\frac{\alpha s I_{e}}{\alpha+\theta}\right) \\
\left.\quad-\frac{\theta s I_{e} D T^{2}}{2(\alpha+\theta)}-K\right\},
\end{aligned}
$$

(C) if $T>T_{d}$ and $T>M$, then

$$
\begin{aligned}
\Pi(T)=\Pi_{3}(T) \\
=\frac{1}{T}\left\{\frac{D F}{(\alpha+\theta)^{2}}\left(e^{(\alpha+\theta) T}-1\right)\right. \\
+\frac{D}{(\alpha+\theta)^{2}}\left(e^{(\alpha+\theta)(T-M)}-1\right)\left(\frac{\alpha s I_{e}}{\alpha+\theta}-c I_{p}\right) \\
+\frac{D T}{\alpha+\theta}\left(h+\theta s+c I_{p}\right)+\frac{D M}{\alpha+\theta}\left(\frac{\alpha s I_{e}}{\alpha+\theta}-c I_{p}\right) \\
\left.+\frac{\theta s I_{e} D M^{2}}{2(\alpha+\theta)}-K\right\},
\end{aligned}
$$

where the meaning of notations $E$ and $F$ in the above expressions is

$$
\begin{aligned}
& E=\alpha s-(\alpha+\theta) c-h-c I_{p}, \\
& F=\alpha s-(\alpha+\theta) c-h+\alpha s I_{e} M-\frac{\alpha s I_{e}}{\alpha+\theta} .
\end{aligned}
$$

For convenience, we will consider the problem through the two following situations: (1) $M \geq T_{d}$ and (2) $M<T_{d}$.

(1) Suppose That $M \geq T_{d}$. In the situation of $M \geq T_{d}$, $\Pi(T)$ has three different expressions as follows:

$$
\begin{array}{ll}
\Pi(T)=\Pi_{1}(T), \quad & 0<T \leq T_{d}, \\
\Pi(T)=\Pi_{2}(T), & T_{d} \leq T \leq M, \\
\Pi(T)=\Pi_{3}(T), & T \geq M .
\end{array}
$$

It is easy to verify that, in the case of $M \geq T_{d}, \Pi(T)$ continues except at $T=T_{d}$. In fact, if $c I_{p} \geq s I_{e}$ then we could prove that $\Pi_{1}\left(T_{d}\right)<\Pi_{2}\left(T_{d}\right)$. (Proof of $\Pi_{1}\left(T_{d}\right)<\Pi_{2}\left(T_{d}\right)$ is shown in Appendix A.)

(2) Suppose That $M<T_{d}$. If $M<T_{d}$, then $\Pi(T)$ has two different expressions as follows:

$$
\begin{array}{ll}
\Pi(T)=\Pi_{1}(T), & 0<T \leq T_{d}, \\
\Pi(T)=\Pi_{3}(T), & T \geq T_{d} .
\end{array}
$$

Here, $\Pi_{1}(T)$ and $\Pi_{3}(T)$ are given by (11) and (13), respectively. $\Pi(T)$ continues except at $T=T_{d}$. In fact, we could prove that $\Pi_{1}\left(T_{d}\right)<\Pi_{3}\left(T_{d}\right)$ when $M<T_{d}$. (Proof of $\Pi_{1}\left(T_{d}\right)<\Pi_{3}\left(T_{d}\right)$ is shown in Appendix B.)

In the next section, we will determine the retailer's optimal cycle time $T^{*}$ for the above two situations using some algebraic method.

\section{The Solution Procedures}

In order to decide the optimal solution $T^{*}$ of function $\Pi(T)$, we need first to study the properties of function $\Pi_{i}(T)(i=$ $1,2,3)$ on $(0,+\infty)$, respectively. The first-order necessary condition for $\Pi_{1}(T)$ in (11) to be maximum is $d \Pi_{1}(T) / d T=0$, which implies that

$$
\frac{-D E}{(\alpha+\theta)^{2}}\left[(\alpha+\theta) T e^{(\alpha+\theta) T}-e^{(\alpha+\theta) T}+1\right]-K=0 .
$$

For convenience, we set the left-hand expression of (17) as $f_{1}(T)$. Taking the derivative of $f_{1}(T)$ with respect to $T$, we get

$$
\frac{d f_{1}(T)}{d T}=-D E T e^{(\alpha+\theta) T} .
$$

From (18) we know that if $E<0$, then $d f_{1}(T) / d T>$ 0 ; that is, $f_{1}(T)$ is increasing on $(0,+\infty)$. It is obvious that $f_{1}(0)=-K<0$ and $\lim _{T \rightarrow+\infty} f_{1}(T)=+\infty$; therefore the Intermediate Value Theorem implies that $f_{1}(T)=0$, that 
is, $d \Pi_{1}(T) / d T=0$, has a unique root (say $\left.T_{1}^{0}\right)$ on $(0,+\infty)$. Moreover, taking the second derivative of $\Pi_{1}(T)$ with respect to $T$ gives

$$
\begin{aligned}
\frac{d^{2} \Pi_{1}(T)}{d T^{2}}= & -\frac{2 K}{T^{3}}+\frac{D E}{(\alpha+\theta)^{2} T^{3}} \\
& \times\left[(\alpha+\theta)^{2} T^{2} e^{(\alpha+\theta) T}-2(\alpha+\theta) T e^{(\alpha+\theta) T}\right. \\
& \left.+2 e^{(\alpha+\theta) T}-2\right] .
\end{aligned}
$$

It is easy to show that the inequality $x^{2} e^{x}-2 x e^{x}+2 e^{x}-2>$ 0 holds for all $x>0$, so $d^{2} \Pi_{1}(T) / d T^{2}$ will always be negative on $(0,+\infty)$ if $E<0$; that is, $\Pi_{1}(T)$ is convex on $(0,+\infty)$. Therefore, $T_{1}^{0}$ is the unique maximum point of $\Pi_{1}(T)$ on $(0,+\infty)$. But if $E \geq 0$, (18) means that $f_{1}(T)$ is decreasing on $(0,+\infty)$; since $f_{1}(0)=-K<0$, then $f_{1}(T)$ is negative and $d \Pi_{1}(T) / d T$ is positive for all $T>0$; hence $\Pi_{1}(T)$ is strictly increasing on $(0,+\infty)$.

Then we have the following lemma to describe the property of $\Pi_{1}(T)$ on $(0,+\infty)$.

Lemma 1. If $E<0, \Pi_{1}(T)$ is convex on $(0,+\infty)$ and $T_{1}^{0}$ is the unique maximum point of $\Pi_{1}(T)$. Otherwise, $\Pi_{1}(T)$ is strictly increasing on $(0,+\infty)$.

Similarly, the first-order necessary condition for $\Pi_{2}(T)$ in (12) to be maximized is $d \Pi_{2}(T) / d T=0$, which leads to

$$
\begin{gathered}
\frac{-D F}{(\alpha+\theta)^{2}}\left[(\alpha+\theta) T e^{(\alpha+\theta) T}-e^{(\alpha+\theta) T}+1\right] \\
+\frac{\theta s I_{e} D T^{2}}{2(\alpha+\theta)}-K=0 .
\end{gathered}
$$

We set the left-hand expression of (20) as $f_{2}(T)$. Taking the first derivative of $f_{2}(T)$ with respect to $T$ gives

$$
\frac{d f_{2}(T)}{d T}=-\left(F e^{(\alpha+\theta) T}-\frac{\theta s I_{e}}{\alpha+\theta}\right) D T .
$$

Consequently, from the sign of $F$ there are two distinct cases for finding the property of $\Pi_{2}(T)$ as follows.

(1) When $F \leq 0$, we have $d f_{2}(T) / d T>0$; that is, $f_{2}(T)$ is strictly increasing on $(0,+\infty)$. Since $f_{2}(0)=-K<0$ and $\lim _{T \rightarrow+\infty} f_{2}(T)=+\infty, f_{2}(T)=0$ has a unique solution (say $T_{2}^{0}$ ) on $(0,+\infty)$. Moreover, from (13) we have

$$
\begin{aligned}
\frac{d^{2} \Pi_{2}(T)}{d T^{2}}= & -\frac{2 K}{T^{3}}+\frac{D F}{(\alpha+\theta)^{2} T^{3}} \\
& \times\left[(\alpha+\theta)^{2} T^{2} e^{(\alpha+\theta) T}-2(\alpha+\theta) T e^{(\alpha+\theta) T}\right. \\
& \left.+2 e^{(\alpha+\theta) T}-2\right] .
\end{aligned}
$$

Since $F \leq 0$ and $(\alpha+\theta)^{2} T^{2} e^{(\alpha+\theta) T}-2(\alpha+\theta) T e^{(\alpha+\theta) T}+$ $2 e^{(\alpha+\theta) T}-2>0$, we get $d^{2} \Pi_{2}(T) / d T^{2}<0$. Hence, $\Pi_{2}(T)$ is convex on $(0,+\infty)$ and $T_{2}^{0}$ is the unique maximum point of $\Pi_{2}(T)$.
(2) When $F>0$, there will exist a unique root to the equation $d f_{2}(T) / d T=0$. Denote this root by $T^{\#}$; then

$$
T^{\#}=\frac{1}{\alpha+\theta}\left[\ln \theta s I_{e}-\ln (\alpha+\theta) F\right]
$$

(A) If $T^{\#} \geq 0$, that is $0<F \leq \theta s I_{e} /(\alpha+\theta)$, then $d f_{2}(T) / d T>0$ for $T \in\left(0, T^{\#}\right)$ and $d f_{2}(T) / d T<$ 0 for $T \in\left(T^{\#},+\infty\right)$; that is, $f_{2}(T)$ is increasing on $\left(0, T^{\#}\right)$ and decreasing on $\left(T^{\#},+\infty\right)$.

(a) When $f_{2}\left(T^{\#}\right)>0, f_{2}(T)=0$ has a unique $\operatorname{root}\left(\operatorname{say} T_{2}^{1}\right)$ on $\left(0, T^{\#}\right)$ due to $f_{2}(0)=-K<$ 0 . Hence, $\Pi_{2}(T)$ is increasing on $\left(0, T_{2}^{1}\right)$ and decreasing on $\left(T_{2}^{1}, T^{\#}\right)$. On the other interval of $\left(T^{\#},+\infty\right)$, however, because of $f_{2}\left(T^{\#}\right)>0$ and $\lim _{T \rightarrow+\infty} f_{2}(T)=-\infty$ for $F>0, f_{2}(T)$ has a unique zero point (say $T_{2}^{2}$ ) on $\left(T^{\#},+\infty\right)$ ). Thus, $\Pi_{2}(T)$ is decreasing on $\left(T^{\#}, T_{2}^{2}\right)$ and increasing on $\left(T_{2}^{2},+\infty\right)$. Hence, $\Pi_{2}(T)$ is increasing on $\left(0, T_{2}^{1}\right)$, decreasing on $\left(T_{2}^{1}, T_{2}^{2}\right)$, and increasing on $\left(T_{2}^{2},+\infty\right)$.

(b) When $f_{2}\left(T^{\#}\right) \leq 0, f_{2}(T)$ is negative on $\left(0, T^{\#}\right)$ because $f_{2}(T)$ is increasing on $\left(0, T^{\#}\right)$, whereas $f_{2}(T)$ is also negative on $\left(T^{\#},+\infty\right)$ since $f_{2}(T)$ is decreasing on $\left(T^{\#},+\infty\right)$. Therefore, $f_{2}(T)$ is always nonpositive on $(0,+\infty)$ and $\Pi_{2}(T)$ is increasing on $(0,+\infty)$.

(B) If $T^{\#}<0$, that is, $F>\theta s I_{e} /(\alpha+\theta)$, then for any $T \geq 0$ we have $d f_{2}(T) / d T<0$; that is, $f_{2}(T)$ is strictly decreasing on $(0,+\infty)$. Since $f_{2}(0)=$ $-K<0, f_{2}(T)$ is negative on $(0,+\infty)$. Hence $\Pi_{2}(T)$ is increasing on $(0,+\infty)$.

Then we have the following lemma to describe the property of $\Pi_{2}(T)$ on $(0,+\infty)$.

Lemma 2. (1) For $F \leq 0, \Pi_{2}(T)$ is convex on $(0,+\infty)$ and $T_{2}^{0}$ is the unique maximum point of $\Pi_{2}(T)$.

(2) For $0<F \leq \theta s I_{e} /(\alpha+\theta), \Pi_{2}(T)$ is increasing on $\left(0, T_{2}^{1}\right)$, decreasing on $\left(T_{2}^{1}, T_{2}^{2}\right)$, and increasing on $\left(T_{2}^{2},+\infty\right)$ if $f_{2}\left(T^{\#}\right)>$ 0 , and $\Pi_{2}(T)$ is increasing on $(0,+\infty)$ otherwise.

(3) For $F>\theta s I_{e} /(\alpha+\theta), \Pi_{2}(T)$ is always increasing on $(0,+\infty)$.

Likewise, the first-order necessary condition for $\Pi_{3}(T)$ in (13) to be maximum is $d \Pi_{3}(T) / d T=0$, which implies that

$$
\begin{aligned}
& \frac{D F\left(e^{(\alpha+\theta) T}-1\right)}{(\alpha+\theta)^{2}}[1-(\alpha+\theta) T]-\frac{D F T}{\alpha+\theta} \\
& +\frac{D}{(\alpha+\theta)^{2}}\left(e^{(\alpha+\theta)(T-M)}-1\right)\left(\frac{\alpha s I_{e}}{\alpha+\theta}-c I_{p}\right)
\end{aligned}
$$




$$
\begin{aligned}
& {[1-(\alpha+\theta) T]-\frac{D(T-M)}{\alpha+\theta}\left(\frac{\alpha s I_{e}}{\alpha+\theta}-c I_{p}\right)} \\
& +\frac{\theta s I_{e} D M^{2}}{2(\alpha+\theta)}-K=0 .
\end{aligned}
$$

We set the left-hand expression of (24) as $f_{3}(T)$. Taking the first derivative of $f_{3}(T)$ with respect to $T$ gives

$$
\frac{d f_{3}(T)}{d T}=-\left[F+\left(\frac{\alpha s I_{e}}{\alpha+\theta}-c I_{p}\right) e^{-(\alpha+\theta) M}\right] D T e^{(\alpha+\theta) T} .
$$

We consider the following two cases.

(1) If $F \leq\left(c I_{p}-\alpha s I_{e} /(\alpha+\theta)\right) e^{-(\alpha+\theta) M}$, then $d f_{3}(T) / d T \geq$ 0 . Therefore, $f_{3}(T)$ is increasing on $(0,+\infty)$. It is easy to get $f_{3}(0)=\left(D /(\alpha+\theta)^{2}\right)\left(e^{-(\alpha+\theta) M}-1\right)\left(\alpha s I_{e} /(\alpha+\right.$ $\left.\theta)-c I_{p}\right)+\theta s I_{e} D M^{2} / 2(\alpha+\theta)+\alpha s I_{e} D M /(\alpha+\theta)^{2}-$ $c I_{p} D M /(\alpha+\theta)-K$ and $\lim _{T \rightarrow+\infty} f_{3}(T)=+\infty$. Thus, if $f_{3}(0)<0$ then $f_{3}(T)=0$ has a unique solution ( say $T_{3}^{0}$ ) on $(0,+\infty)$. Hence, $f_{3}(T)$ will be negative on $\left(0, T_{3}^{0}\right)$ and positive on $\left(T_{3}^{0},+\infty\right)$, which implies $\Pi_{3}(T)$ is increasing on $\left(0, T_{3}^{0}\right)$ and decreasing on $\left(T_{3}^{0},+\infty\right)$. That is, $\Pi_{3}(T)$ is unimodal on $(0,+\infty)$ and $T_{3}^{0}$ is the unique maximum point of $\Pi_{3}(T)$ if $f_{3}(0)<0$. In contrast, if $f_{3}(0) \geq 0$ then $f_{3}(T)$ will always be nonnegative on $(0,+\infty)$; hence $\Pi_{3}(T)$ is always decreasing on $(0,+\infty)$.

(2) If $F>\left(c I_{p}-\alpha s I_{e} /(\alpha+\theta)\right) e^{-(\alpha+\theta) M}$, then $f_{3}(T)$ is strictly decreasing on $(0,+\infty)$. Noting that $\lim _{T \rightarrow+\infty} f_{3}(T)=$ $-\infty$ for $F>-\left(\alpha s I_{e} /(\alpha+\theta)-c I_{p}\right) e^{-(\alpha+\theta) M}$, one easily obtains that if $f_{3}(0)>0$ there will exist a unique root (say $\left.T_{3}^{1}\right)$ to the equation $f_{3}(T)=0$; hence $f_{3}(T)$ is positive on $\left(0, T_{3}^{1}\right)$ and negative on $\left(T_{3}^{1},+\infty\right)$, which implies $\Pi_{3}(T)$ is decreasing on $\left(0, T_{3}^{1}\right)$ and increasing on $\left(T_{3}^{1},+\infty\right)$. But if $f_{3}(0) \leq 0, f_{3}(T)$ is always negative on $(0,+\infty)$; then $\Pi_{3}(T)$ is increasing on $(0,+\infty)$.

Summarizing the above arguments, the following lemma to describe the property of $\Pi_{3}(T)$ on $(0,+\infty)$ will be obtained.

Lemma 3. (1) For $F \leq\left(c I_{p}-\alpha s I_{e} /(\alpha+\theta)\right) e^{-(\alpha+\theta) M}, \Pi_{3}(T)$ is increasing on $\left(0, T_{3}^{0}\right)$ and decreasing on $\left(T_{3}^{0},+\infty\right)$ if $f_{3}(0)<0$, and $\Pi_{3}(T)$ is decreasing on $(0,+\infty)$ otherwise.

(2) For $F>\left(c I_{p}-\alpha s I_{e} /(\alpha+\theta)\right) e^{-(\alpha+\theta) M}, \Pi_{3}(T)$ is decreasing on $\left(0, T_{3}^{1}\right)$ and increasing on $\left(T_{3}^{1},+\infty\right)$ if $f_{3}(0)>0$, and $\Pi_{3}(T)$ is increasing on $(0,+\infty)$ otherwise.

Based upon Lemmas 1-3, we now will decide the optimal solution $T^{*}$ to $\Pi(T)$ from the below two situations.

4.1. Decision Rule of the Optimal Cycle Time $T^{*}$ When $M \geq$ $T_{d}$. When $M \geq T_{d}$, the piecewise profit function $\Pi(T)$ has three different expressions, that is, $\Pi_{1}(T), \Pi_{2}(T)$, and $\Pi_{3}(T)$, respectively. From (17), (20), and (24), we have

$$
\begin{aligned}
f_{1}\left(T_{d}\right)= & \frac{-D E}{(\alpha+\theta)^{2}}\left[(\alpha+\theta) T_{d} e^{(\alpha+\theta) T_{d}}-e^{(\alpha+\theta) T_{d}}+1\right]-K \\
f_{2}\left(T_{d}\right)= & \frac{-D F}{(\alpha+\theta)^{2}}\left[(\alpha+\theta) T_{d} e^{(\alpha+\theta) T_{d}}-e^{(\alpha+\theta) T_{d}}+1\right] \\
& +\frac{\theta s I_{e} D T_{d}^{2}}{2(\alpha+\theta)}-K, \\
f_{2}(M)= & f_{3}(M) \\
= & \frac{-D F}{(\alpha+\theta)^{2}}\left[(\alpha+\theta) M e^{(\alpha+\theta) M}-e^{(\alpha+\theta) M}+1\right] \\
& +\frac{\theta s I_{e} D M^{2}}{2(\alpha+\theta)}-K .
\end{aligned}
$$

As shown in Appendix C, we will find that $f_{1}\left(T_{d}\right)>f_{2}\left(T_{d}\right)$. For convenience, we rewrite the notation $E$ as $E=F-c I_{p}+$ $\alpha s I_{e} /(\alpha+\theta)-\alpha s I_{e} M$, and the following two theorems would be obtained to decide the optimal solution $T^{*}$ when $M \geq T_{d}$.

Theorem 4. If $M \geq T_{d}$ and $\left(\theta s I_{e} /(\alpha+\theta)\right) e^{-(\alpha+\theta) T_{d}} \leq\left(c I_{p}-\right.$ $\left.\alpha s I_{e} /(\alpha+\theta)\right) e^{-(\alpha+\theta) M}$, then one has the following results.

(1) When $F \leq\left(\theta s I_{e} /(\alpha+\theta)\right) e^{-(\alpha+\theta) M}$, the following applies.

(A) If $f_{1}\left(T_{d}\right) \leq 0, f_{2}\left(T_{d}\right)<0$, and $f_{2}(M) \leq 0$, then $\Pi\left(T^{*}\right)=\Pi_{3}\left(T_{3}^{0}\right)$. Hence $T^{*}$ is $T_{3}^{0}$.

(B) If $f_{1}\left(T_{d}\right) \leq 0, f_{2}\left(T_{d}\right)<0$, and $f_{2}(M)>0$, then $\Pi\left(T^{*}\right)=\Pi_{2}\left(T_{2}^{3}\right)$. Hence $T^{*}$ is $T_{2}^{3}$, where $T_{2}^{3} \in$ $\left(T_{d}, M\right)$ and satisfies (20).

(C) If $f_{1}\left(T_{d}\right)>0, f_{2}\left(T_{d}\right)<0$, and $f_{2}(M)>0$, then $\Pi\left(T^{*}\right)=\max \left\{\Pi_{1}\left(T_{1}^{0}\right), \Pi_{2}\left(T_{2}^{3}\right)\right\}$. Hence $T^{*}$ is $T_{1}^{0}$ or $T_{2}^{3}$ associated with maximum profit.

(D) If $f_{1}\left(T_{d}\right)>0, f_{2}\left(T_{d}\right)<0$, and $f_{2}(M) \leq 0$, then $\Pi\left(T^{*}\right)=\max \left\{\Pi_{1}\left(T_{1}^{0}\right), \Pi_{3}\left(T_{3}^{0}\right)\right\}$. Hence $T^{*}$ is $T_{1}^{0}$ or $T_{3}^{0}$ associated with maximum profit.

(E) If $f_{1}\left(T_{d}\right)>0, f_{2}\left(T_{d}\right) \geq 0$, and $f_{2}(M)>0$, then $\Pi\left(T^{*}\right)=\max \left\{\Pi_{1}\left(T_{1}^{0}\right), \Pi_{2}(T d)\right\}$. Hence $T^{*}$ is $T_{1}^{0}$ or $T_{d}$ associated with maximum profit.

(2) When $\left(\theta s I_{e} /(\alpha+\theta)\right) e^{-(\alpha+\theta) M}<F \leq\left(\theta s I_{e} /(\alpha+\right.$ $\theta)) e^{-(\alpha+\theta) T_{d}}$, the following applies.

(A) While $f_{2}\left(T^{\#}\right)>0$, one has the following.

(a) If $f_{1}\left(T_{d}\right) \leq 0, f_{2}\left(T_{d}\right)<0$, and $f_{2}(M) \leq 0$, then $\Pi\left(T^{*}\right)=\max \left\{\Pi_{2}\left(T_{2}^{1}\right), \Pi_{3}\left(T_{3}^{0}\right)\right\}$. Hence $T^{*}$ is $T_{2}^{1}$ or $T_{3}^{0}$ associated with maximum profit.

(b) If $f_{1}\left(T_{d}\right) \leq 0, f_{2}\left(T_{d}\right)<0$, and $f_{2}(M)>0$, then $\Pi\left(T^{*}\right)=\Pi_{2}\left(T_{2}^{1}\right)$. Hence $T^{*}$ is $T_{2}^{1}$. 
(c) If $f_{1}\left(T_{d}\right)>0, f_{2}\left(T_{d}\right)<0$, and $f_{2}(M) \leq$ 0 , then $\Pi\left(T^{*}\right)=\max \left\{\Pi_{1}\left(T_{1}^{0}\right), \Pi_{2}\left(T_{2}^{1}\right)\right.$, $\Pi_{3}\left(T_{3}^{0}\right)$ \}. Hence $T^{*}$ is $T_{1}^{0}, T_{2}^{1}$, or $T_{3}^{0}$ associated with maximum profit.

(d) If $f_{1}\left(T_{d}\right)>0, f_{2}\left(T_{d}\right)<0$, and $f_{2}(M)>0$, then $\Pi\left(T^{*}\right)=\max \left\{\Pi_{1}\left(T_{1}^{0}\right), \Pi_{2}\left(T_{2}^{1}\right)\right\}$. Hence $T^{*}$ is $T_{1}^{0}$ or $T_{2}^{1}$ associated with maximum profit.

(e) If $f_{1}\left(T_{d}\right)>0, f_{2}\left(T_{d}\right) \geq 0$, and $f_{2}(M) \leq$ 0 , then $\Pi\left(T^{*}\right)=\max \left\{\Pi_{1}\left(T_{1}^{0}\right), \Pi_{2}\left(T_{d}\right)\right.$, $\left.\Pi_{3}\left(T_{3}^{0}\right)\right\}$. Hence $T^{*}$ is $T_{1}^{0}, T_{d}$, or $T_{3}^{0}$ associated with maximum profit.

(f) If $f_{1}\left(T_{d}\right)>0, f_{2}\left(T_{d}\right) \geq 0$, and $f_{2}(M)>0$, then $\Pi\left(T^{*}\right)=\max \left\{\Pi_{1}\left(T_{1}^{0}\right), \Pi_{2}\left(T_{d}\right)\right\}$. Hence $T^{*}$ is $T_{1}^{0}$ or $T_{d}$ associated with maximum profit.

(B) While $f_{2}\left(T^{\#}\right) \leq 0$, one has the following.

(a) If $f_{1}\left(T_{d}\right) \leq 0, f_{2}\left(T_{d}\right)<0$, and $f_{2}(M)<0$, then $\Pi\left(T^{*}\right)=\Pi_{3}\left(T_{3}^{0}\right)$. Hence $T^{*}$ is $T_{3}^{0}$.

(b) If $f_{1}\left(T_{d}\right)>0, f_{2}\left(T_{d}\right)<0$, and $f_{2}(M)<0$, then $\Pi\left(T^{*}\right)=\max \left\{\Pi_{1}\left(T_{1}^{0}\right), \Pi_{3}\left(T_{3}^{0}\right)\right\}$. Hence $T^{*}$ is $T_{1}^{0}$ or $T_{3}^{0}$ associated with maximum profit.

(3) When $\left(\theta s I_{e} /(\alpha+\theta)\right) e^{-(\alpha+\theta) T_{d}}<F \leq\left(c I_{p}-\alpha s I_{e} /(\alpha+\right.$ $\theta)) e^{-(\alpha+\theta) M}$, the following applies.

(A) If $f_{1}\left(T_{d}\right) \leq 0, f_{2}\left(T_{d}\right)<0$, and $f_{2}(M)<0$, then $\Pi\left(T^{*}\right)=\Pi_{3}\left(T_{3}^{0}\right)$. Hence $T^{*}$ is $T_{3}^{0}$.

(B) If $f_{1}\left(T_{d}\right)>0, f_{2}\left(T_{d}\right)<0$, and $f_{2}(M)<0$, then $\Pi\left(T^{*}\right)=\max \left\{\Pi_{1}\left(T_{1}^{0}\right), \Pi_{3}\left(T_{3}^{0}\right)\right\}$. Hence $T^{*}$ is $T_{1}^{0}$ or $T_{3}^{0}$ associated with maximum profit.

(C) If $f_{1}\left(T_{d}\right)>0, f_{2}\left(T_{d}\right) \geq 0$, and $f_{2}(M)<0$, then $\Pi\left(T^{*}\right)=\max \left\{\Pi_{1}\left(T_{1}^{0}\right), \Pi_{2}\left(T_{d}\right), \Pi_{3}\left(T_{3}^{0}\right)\right\}$. Hence $T^{*}$ is $T_{1}^{0}, T_{d}$, or $T_{3}^{0}$ associated with maximum profit.

(D) If $f_{1}\left(T_{d}\right)>0, f_{2}\left(T_{d}\right) \geq 0$, and $f_{2}(M) \geq 0$, then $\Pi\left(T^{*}\right)=\max \left\{\Pi_{1}\left(T_{1}^{0}\right), \Pi_{2}\left(T_{d}\right)\right\}$. Hence $T^{*}$ is $T_{1}^{0}$ or $T_{d}$ associated with maximum profit.

(4) When $F>\left(c I_{p}-\alpha s I_{e} /(\alpha+\theta)\right) e^{-(\alpha+\theta) M}, T^{*}$ is $+\infty$.

Proof. See Appendix E for detail.

Theorem 5. If $M \geq T_{d}$ and $\left(\theta s I_{e} /(\alpha+\theta)\right) e^{-(\alpha+\theta) T_{d}}>\left(c I_{p}-\right.$ $\left.\theta s I_{e} /(\alpha+\theta)\right) e^{-(\alpha+\theta) M}$, then one has the following results.

(1) When $F \leq\left(\theta s I_{e} /(\alpha+\theta)\right) e^{-(\alpha+\theta) M}$, the results are the same as (1) in Theorem 4.

(2) When $\left(\theta s I_{e} /(\alpha+\theta)\right) e^{-(\alpha+\theta) M}<F \leq\left(c I_{p}-\right.$ $\left.\alpha s I_{e} /(\alpha+\theta)\right) e^{-(\alpha+\theta) M}$, the results are the same as (2) in Theorem 4.

(3) When $F>\left(c I_{p}-\alpha s I_{e} /(\alpha+\theta)\right) e^{-(\alpha+\theta) M}, T^{*}$ is $+\infty$.

Proof. See Appendix E for detail.
4.2. Decision Rule of the Optimal Cycle Time $T^{*}$ When $M<$ $T_{d}$. When $M<T_{d}$, the piecewise profit function $\Pi(T)$ has only two different expressions, that is, $\Pi_{1}(T)$ and $\Pi_{3}(T)$, respectively. From (24), we have

$$
\begin{aligned}
f_{3}\left(T_{d}\right)= & \frac{D F\left(e^{(\alpha+\theta) T_{d}}-1\right)}{(\alpha+\theta)^{2}}\left[1-(\alpha+\theta) T_{d}\right]-\frac{D F T_{d}}{\alpha+\theta} \\
& +\frac{D}{(\alpha+\theta)^{2}}\left(e^{(\alpha+\theta)\left(T_{d}-M\right)}-1\right)\left(\frac{\alpha s I_{e}}{\alpha+\theta}-c I_{p}\right) \\
& {\left[1-(\alpha+\theta) T_{d}\right]-\frac{D\left(T_{d}-M\right)}{\alpha+\theta}\left(\frac{\alpha s I_{e}}{\alpha+\theta}-c I_{p}\right) } \\
& +\frac{\theta s I_{e} D M^{2}}{2(\alpha+\theta)}-K .
\end{aligned}
$$

As shown in Appendix $\mathrm{D}$, we will find that $f_{1}\left(T_{d}\right)>$ $f_{3}\left(T_{d}\right)$. The following theorem would be given to decide the system's optimal cycle time $T^{*}$ when $M<T_{d}$.

Theorem 6. If $M<T_{d}$, then one has the following results.

(1) When $F \leq\left(c I_{p}-\alpha s I_{e} /(\alpha+\theta)\right) e^{-(\alpha+\theta) M}$, the following applies.

(A) If $f_{1}\left(T_{d}\right) \leq 0$ and $f_{3}\left(T_{d}\right)<0$, then $\Pi\left(T^{*}\right)=$ $\Pi_{3}\left(T_{3}^{0}\right)$. Hence $T^{*}$ is $T_{3}^{0}$.

(B) If $f_{1}\left(T_{d}\right)>0$ and $f_{3}\left(T_{d}\right) \geq 0$, then $\Pi\left(T^{*}\right)=$ $\max \left\{\Pi_{1}\left(T_{1}^{0}\right), \Pi_{3}(T d)\right\}$. Hence $T^{*}$ is $T_{1}^{0}$ or $T_{d}$ associated with the maximum profit.

(C) If $f_{1}\left(T_{d}\right)>0$ and $f_{3}\left(T_{d}\right)<0$, then $\Pi\left(T^{*}\right)=$ $\max \left\{\Pi_{1}\left(T_{1}^{0}\right), \Pi_{3}\left(T_{3}^{0}\right)\right\}$. Hence $T^{*}$ is $T_{1}^{0}$ or $T_{3}^{0}$ associated with the maximum profit.

(2) When $F>\left(c I_{p}-\alpha s I_{e} /(\alpha+\theta)\right) e^{-(\alpha+\theta) M}, T^{*}$ is $+\infty$.

Proof. See Appendix F for detail.

\section{Numerical Example}

In this section, we will provide the following numerical example to illustrate the present model.

Example 1. Given $Q_{d}=200$ units, $D=1500$ units, $\alpha=$ $0.4, \theta=0.20, K=\$ 50, h=\$ 1 /$ unit $/$ year, $c=\$ 5$ per unit, $s=\$ 9$ per unit, $I_{e}=0.13 / \$ /$ year, $I_{p}=0.19 / \$ /$ year, and $M=0.3$ year, it is easy to get $T_{d}=0.2123,\left(\theta s I_{e} /(\alpha+\right.$ $\theta)) e^{-(\alpha+\theta) T_{d}} \leq\left(c I_{p}-\alpha s I_{e} /(\alpha+\theta)\right) e^{-(\alpha+\theta) M}$, and $F \leq\left(\theta s I_{e} /(\alpha+\right.$ $\theta) e^{-(\alpha+\theta) M}$. Consequently, by using Bisection method or Newton-Raphson method we could obtain $T_{1}^{0}=0.1760$, $T_{2}^{0}=0.1892$, and $T_{3}^{0}=0.1931$. Because of $f_{1}\left(T_{d}\right) \leq 0$, $f_{2}\left(T_{d}\right)<0$, and $f_{2}(M) \leq 0$, according to Theorem 4(1) the retailer's optimal cycle time should be $T^{*}=T_{3}^{0}=0.1931$; 
TABLE 1: The impact of change of $\alpha, \theta, Q_{d}$, and $M$ on the optimal solutions.

\begin{tabular}{|c|c|c|c|c|c|c|c|}
\hline & Parameters & $T_{1}^{0}$ & $T_{2}^{0}$ & $T_{3}^{0}$ & $T^{*}$ & $Q^{*}$ & $\Pi^{*}$ \\
\hline \multirow{6}{*}{$\alpha$} & 0.1 & 0.3381 & 0.3637 & 0.3895 & 0.3637 & 69.5772 & 602.3591 \\
\hline & 0.2 & 0.4467 & 0.3956 & 0.3957 & 0.3956 & 82.3678 & 621.7691 \\
\hline & 0.3 & 0.4792 & 0.4231 & 0.4320 & 0.4231 & 89.5987 & 643.0335 \\
\hline & 0.4 & 0.5561 & 0.4538 & 0.4439 & 0.4538 & 98.5672 & 666.3862 \\
\hline & 0.5 & 0.6723 & 0.5562 & 0.5071 & 0.5071 & 103.3781 & 693.1645 \\
\hline & 0.6 & 0.8552 & 0.5781 & 0.6047 & 0.6032 & 136.7563 & 736.2176 \\
\hline \multirow{6}{*}{$\theta$} & 0.01 & 0.5651 & 0.4436 & 0.5008 & 0.4436 & 109.8853 & 772.1683 \\
\hline & 0.02 & 0.5513 & 0.4471 & 0.4973 & 0.4471 & 106.4786 & 743.9053 \\
\hline & 0.05 & 0.5167 & 0.4441 & 0.4812 & 0.4441 & 99.4372 & 726.8573 \\
\hline & 0.10 & 0.4783 & 0.4368 & 0.4791 & 0.4368 & 97.9335 & 708.2341 \\
\hline & 0.50 & 0.3365 & 0.3568 & 0.4659 & 0.3568 & 83.3563 & 688.7732 \\
\hline & 1.00 & 0.3561 & 0.2896 & 0.4543 & 0.3561 & 71.0856 & 662.5568 \\
\hline \multirow{6}{*}{$Q_{d}$} & 50 & 0.2344 & 0.2432 & 0.2589 & 0.2344 & 46.3085 & 432.9953 \\
\hline & 100 & 0.3832 & 0.3565 & 0.3867 & 0.3565 & 75.0255 & 394.8304 \\
\hline & 150 & 0.4973 & 0.4236 & 0.4973 & 0.4236 & 91.9334 & 343.0035 \\
\hline & 200 & 0.6601 & 0.5467 & 0.5675 & 0.5675 & 127.6297 & 321.5728 \\
\hline & 250 & 0.7756 & 0.6873 & 0.6981 & 0.6981 & 163.3156 & 283.3270 \\
\hline & 300 & 0.8132 & 0.7675 & 0.7321 & 0.7321 & 192.7368 & 217.3673 \\
\hline \multirow{6}{*}{$M$} & 0.1 & 0.3726 & 0.3826 & 0.2873 & 0.3826 & 73.7665 & 274.6542 \\
\hline & 0.2 & 0.3875 & 0.3835 & 0.3965 & 0.3835 & 79.9762 & 282.3871 \\
\hline & 0.3 & 0.3811 & 0.4009 & 0.4623 & 0.4009 & 83.3721 & 290.2323 \\
\hline & 0.4 & 0.3765 & 0.4197 & 0.4987 & 0.3765 & 89.9932 & 313.0369 \\
\hline & 0.5 & 0.3732 & 0.4618 & 0.5013 & 0.4618 & 95.5513 & 327.3771 \\
\hline & 0.6 & 0.3586 & 0.4745 & 0.5233 & 0.3586 & 99.8756 & 363.3689 \\
\hline
\end{tabular}

hence the optimal order quantity and the maximum average profit are $Q^{*}=158.8763$ and $\Pi^{*}=1867.3562$, respectively.

Next, we further study the effects of changes of parameters $\alpha, \theta, Q_{d}$, and $M$ on the optimal solutions. The values of other parameters keep the same as in the above example when each of parameters $\alpha, \theta, Q_{d}$, and $M$ varies. Table 1 presents the observed results with various parameters $\alpha, \theta, Q_{d}$, and $M$.

The following inferences can be made based on Table 1.

(1) The retailer's optimal order quantity $Q^{*}$ and the optimal average profit $\Pi^{*}$ increase as the value of $\alpha$ increases. It implies that when the market demand is more sensitive to the inventory level, the retailer will increase his/her order quantity to make more profit under permissible delay in payments.

(2) The optimal order quantity $Q^{*}$ and the maximum average profit $\Pi^{*}$ decrease as the value of $\theta$ increases.

(3) When $Q_{d}$ increases, the optimal order quantity $Q^{*}$ and the optimal cycle time $T^{*}$ are increasing but the optimal average profit $\Pi^{*}$ is decreasing.

(4) The retailer's order quantity $Q^{*}$ is increasing as $M$ increases. This verifies the fact that the retailer could indeed increase the sales quantity by adopting the trade credit policy provided by his/her supplier.

\section{Conclusions}

In this paper, we develop an EOQ model for deteriorating items under permissible delay in payments. The primary difference of this paper as compared to previous related studies is the following four aspects: (1) the demand rate of items is dependent on the retailer's current stock level, (2) many items deteriorate continuously such as fruits and vegetables, (3) the retailer who purchases the items enjoys a fixed credit period offered by the supplier if the order quantity is greater than or equal to the predetermined quantity, and (4) we here use maximizing profit as the objective to find the optimal replenishment policies, which could better describe the essence of the inventory system than a cost-minimization model. In addition, we have discussed in detail the conditions of the existence and uniqueness of the optimal solutions to the model. Three easy-to-use theorems are developed to find the optimal ordering policies for the considered problem, and these theoretical results are illustrated by numerical example. By studying the effects of $\alpha, \theta, Q_{d}$, and $M$ on the optimal order quantity $Q^{*}$ and the optimal average profit $\Pi^{*}$, some managerial insights are derived.

The presented model can be further extended to some more practical situations. For example, we could allow for shortages, quantity discounts, time value of money and inflation, price-sensitive and stock-dependent demand, and so forth. 


\section{Appendices}

A. Proof of $\Pi_{1}\left(T_{d}\right)<\Pi_{2}\left(T_{d}\right)$

If $c I_{p} \geq s I_{e}$, we have $F-E=\alpha s I_{e} M+c I_{p}-\alpha s I_{e} /(\alpha+\theta)>0$. From (11) and (12), we get

$$
\begin{aligned}
& \Pi_{2}\left(T_{d}\right)- \Pi_{1}\left(T_{d}\right) \\
&=\frac{1}{T_{d}}\left\{\frac{D(F-E)}{(\alpha+\theta)^{2}}\left(e^{(\alpha+\theta) T_{d}}-(\alpha+\theta) T_{d}-1\right)\right. \\
&\left.\quad+s I_{e} M D T_{d}-\frac{\theta s I_{e} D T_{d}^{2}}{2(\alpha+\theta)}\right\} .
\end{aligned}
$$

It is evident that $M \geq T_{d}$ and $\left(e^{(\alpha+\theta) T_{d}}-(\alpha+\theta) T_{d}-1\right)>0$ for $T_{d}>0$; then

$$
\begin{aligned}
& \Pi_{2}\left(T_{d}\right)- \Pi_{1}\left(T_{d}\right) \\
&>\frac{1}{T_{d}}\left\{\frac{D T_{d}^{2}}{2}\left(\alpha s I_{e} M-\frac{\alpha s I_{e}}{\alpha+\theta}+c I_{p}\right)\right. \\
&\left.\quad+s I_{e} D M T_{d}-\frac{\theta s I_{e} D T_{d}^{2}}{2(\alpha+\theta)}\right\} \\
&=\frac{D T_{d}}{2}\left(\alpha s I_{e} M+c I_{p}\right)-\frac{s I_{e} D T_{d}}{2}+s I_{e} D M \\
& \geq \frac{D T_{d}}{2}\left(\alpha s I_{e} M+c I_{p}\right)+\frac{s I_{e} D M}{2}>0 .
\end{aligned}
$$

As a result, we have $\Pi_{1}\left(T_{d}\right)<\Pi_{2}\left(T_{d}\right)$.

This completes the proof of Appendix A.

\section{B. Proof of $\Pi_{1}\left(T_{d}\right)<\Pi_{3}\left(T_{d}\right)$}

If $c I_{p} \geq s I_{e}$, we have $F-E=\alpha s I_{e} M+c I_{p}-\alpha s I_{e} /(\alpha+\theta)>0$. From (11) and (13), we get

$$
\begin{aligned}
\Pi_{3}\left(T_{d}\right)- & \Pi_{1}\left(T_{d}\right) \\
=\frac{1}{T_{d}}\{ & \frac{D(F-E)}{(\alpha+\theta)^{2}}\left[e^{(\alpha+\theta) T_{d}}-e^{(\alpha+\theta)\left(T_{d}-M\right)}-(\alpha+\theta) M\right] \\
& +\frac{\alpha s I_{e} M D}{(\alpha+\theta)^{2}}\left(e^{(\alpha+\theta)\left(T_{d}-M\right)}-1\right) \\
& \left.+\frac{\alpha s I_{e} D M^{2}}{(\alpha+\theta)}+\frac{\theta s I_{e} D M^{2}}{2(\alpha+\theta)}\right\} .
\end{aligned}
$$

Because of $T_{d}>M$ and $e^{(\alpha+\theta) T_{d}}-e^{(\alpha+\theta)\left(T_{d}-M\right)}-(\alpha+\theta) M>0$, we have $\Pi_{3}\left(T_{d}\right)-\Pi_{1}\left(T_{d}\right)>0$.

This completes the proof of Appendix B.
C. Proof of $f_{1}\left(T_{d}\right)>f_{2}\left(T_{d}\right)$

If $c I_{p} \geq s I_{e}$, from (26) and (27), we have

$$
\begin{aligned}
f_{2}\left(T_{d}\right)-f_{1}\left(T_{d}\right) & \\
= & -\frac{D}{(\alpha+\theta)^{2}}\left(\alpha s I_{e} M+c I_{p}-\frac{\alpha s I_{e}}{\alpha+\theta}\right) \\
& \times\left[(\alpha+\theta) T_{d} e^{(\alpha+\theta) T_{d}}-e^{(\alpha+\theta) T_{d}}+1\right]+\frac{\theta s I_{e} D T_{d}^{2}}{2(\alpha+\theta)} \\
\leq & -\frac{D}{(\alpha+\theta)^{2}}\left(\alpha s I_{e} M+\frac{\theta s I_{e}}{\alpha+\theta}\right) \\
& \times\left[(\alpha+\theta) T_{d} e^{(\alpha+\theta) T_{d}}-e^{(\alpha+\theta) T_{d}}+1\right]+\frac{\theta s I_{e} D T_{d}^{2}}{2(\alpha+\theta)} \\
= & -\frac{D s I_{e}}{(\alpha+\theta)^{2}}\left\{\left(\alpha M+\frac{\theta}{\alpha+\theta}\right)\right. \\
\times & \left.\quad \frac{\theta(\alpha+\theta) T_{d}^{2}}{2}\right\} .
\end{aligned}
$$

Let $G\left(T_{d}\right)=(\alpha M+\theta /(\alpha+\theta))\left[(\alpha+\theta) T_{d} e^{(\alpha+\theta) T_{d}}-e^{(\alpha+\theta) T_{d}}+\right.$ 1] $-\theta(\alpha+\theta) T_{d}^{2} / 2$; then

$$
\begin{aligned}
G^{\prime}\left(T_{d}\right) & =\left(\alpha M+\frac{\theta}{\alpha+\theta}\right)(\alpha+\theta)^{2} T_{d} e^{(\alpha+\theta) T_{d}}-\theta(\alpha+\theta) T_{d} \\
& =\theta(\alpha+\theta) T_{d}\left[\left(\frac{\alpha M(\alpha+\theta)}{\theta}+1\right) e^{(\alpha+\theta) T_{d}}-1\right]>0
\end{aligned}
$$

Hence, $G\left(T_{d}\right)>G(0)=0$; that is, $f_{1}\left(T_{d}\right)>f_{2}\left(T_{d}\right)$.

This completes the proof of Appendix C.

\section{Proof of $f_{1}\left(T_{d}\right)>f_{3}\left(T_{d}\right)$}

From (26) and (24), we have

$$
\begin{aligned}
f_{3}\left(T_{d}\right)-f_{1}\left(T_{d}\right) \\
=\frac{D}{(\alpha+\theta)^{2}}\left[(\alpha+\theta) T_{d} e^{(\alpha+\theta) T_{d}}-e^{(\alpha+\theta) T_{d}}+1\right] \\
\quad \times\left(\frac{\alpha s I_{e}}{\alpha+\theta}-c I_{p}-\alpha s I_{e} M\right)-\frac{D}{(\alpha+\theta)^{2}} \\
\\
\quad\left[(\alpha+\theta) T_{d} e^{(\alpha+\theta)\left(T_{d}-M\right)}-e^{(\alpha+\theta)\left(T_{d}-M\right)}+1-(\alpha+\theta) M\right] \\
\quad \times\left(\frac{\alpha s I_{e}}{\alpha+\theta}-c I_{p}\right)+\frac{\theta s I_{e} D M^{2}}{2(\alpha+\theta)} \\
=\frac{D}{(\alpha+\theta)^{2}}\left[(\alpha+\theta) T_{d} e^{(\alpha+\theta) T_{d}}-e^{(\alpha+\theta) T_{d}}\right.
\end{aligned}
$$




$$
\begin{gathered}
-(\alpha+\theta) T_{d} e^{(\alpha+\theta)\left(T_{d}-M\right)} \\
\left.+e^{(\alpha+\theta)\left(T_{d}-M\right)}+(\alpha+\theta) M\right] \\
\left(\frac{\alpha s I_{e}}{\alpha+\theta}-c I_{p}\right)+\frac{\theta s I_{e} D M^{2}}{2(\alpha+\theta)}-\frac{\alpha s I_{e} D M}{(\alpha+\theta)^{2}} \\
\times\left[(\alpha+\theta) T_{d} e^{(\alpha+\theta) T_{d}}-e^{(\alpha+\theta) T_{d}}+1\right] .
\end{gathered}
$$

For $c I_{p} \geq s I_{e}$ and $(\alpha+\theta) T_{d} e^{(\alpha+\theta) T_{d}}-e^{(\alpha+\theta) T_{d}}-(\alpha+$ $\theta) T_{d} e^{(\alpha+\theta)\left(T_{d}-M\right)}+e^{(\alpha+\theta)\left(T_{d}-M\right)}+(\alpha+\theta) M>0$, then

$$
\begin{gathered}
f_{3}\left(T_{d}\right)-f_{1}\left(T_{d}\right) \\
\leq-\frac{\theta s I_{e} D}{(\alpha+\theta)^{3}}\left\{\left(e^{(\alpha+\theta) T_{d}}-e^{(\alpha+\theta)\left(T_{d}-M\right)}\right)\left[(\alpha+\theta) T_{d}-1\right]\right. \\
\left.+(\alpha+\theta) M-\frac{(\alpha+\theta)^{2} M^{2}}{2}\right\} \\
-\frac{\alpha s I_{e} D M}{(\alpha+\theta)^{2}}\left[(\alpha+\theta) T_{d} e^{(\alpha+\theta) T_{d}}-e^{(\alpha+\theta) T_{d}}+1\right] .
\end{gathered}
$$

Let $H\left(T_{d}\right)=\left(e^{(\alpha+\theta) T_{d}}-e^{(\alpha+\theta)\left(T_{d}-M\right)}\right)\left[(\alpha+\theta) T_{d}-1\right]+(\alpha+$ $\theta) M-(\alpha+\theta)^{2} M^{2} / 2$; then it is easy to obtain $H^{\prime}\left(T_{d}\right)=(\alpha+$ $\theta)^{2} T_{d}^{2} e^{(\alpha+\theta) T_{d}}\left(1-e^{(\alpha+\theta) M}\right)>0$ for $T_{d}>0$, so $H\left(T_{d}\right)>H(M)>$ 0 ; hence $f_{1}\left(T_{d}\right)>f_{3}\left(T_{d}\right)$.

This completes the proof of Appendix D.

\section{E. Proof of Theorems 4 and 5}

Before the proof of Theorems 4 and 5, according to the anterior analysis in Section 4, we can get the following results.

(a) If $F<c I_{p}-\alpha s I_{e} /(\alpha+\theta)+\alpha s I_{e} M, f_{1}(T)$ is increasing on $\left(0, T_{d}\right)$. Otherwise, $f_{1}(T)$ is decreasing on $\left(0, T_{d}\right)$.

(b) If $F \leq 0, f_{2}(T)$ is increasing on $\left(T_{d}, M\right)$. Further, if $F>$ 0 and $T^{\#} \geq M$, that is, $0<F \leq\left(\theta s I_{e} /(\alpha+\theta)\right) e^{-(\alpha+\theta) M}$, $f_{2}(T)$ is also increasing on $\left(T_{d}, M\right)$. As a result, if $F \leq\left(\theta s I_{e} /(\alpha+\theta)\right) e^{-(\alpha+\theta) M}$ then $f_{2}(T)$ is always increasing on $\left(T_{d}, M\right)$, and in this case if $f_{2}\left(T_{d}\right)<0$ and $f_{2}(M)>0$ there must exist a unique root to the equation $f_{2}(T)=0$ on $\left(T_{d}, M\right)$, and we denote this root by $T_{2}^{3}$ to differentiate with $T_{2}^{0} \in(0,+\infty)$ and $T_{2}^{1} \in\left(0, T^{\#}\right)$. But if $T_{d} \leq T^{\#}<M$, that is, $\left(\theta s I_{e} /(\alpha+\right.$ $\theta)) e^{-(\alpha+\theta) M}<F \leq\left(\theta s I_{e} /(\alpha+\theta)\right) e^{-(\alpha+\theta) T_{d}}$, then $d f_{2}(T) / d T>0$ for $T \in\left(T_{d}, T^{\#}\right)$ and $d f_{2}(T) / d T<0$ for $T \in\left(T^{\#}, M\right)$. However, when $T^{\#}<T_{d}$, that is, $F>\left(\theta s I_{e} /(\alpha+\theta)\right) e^{-(\alpha+\theta) T_{d}}$, we have $d f_{2}(T) / d T<0$ on $\left(T_{d}, M\right)$, and in this case if $f_{2}\left(T_{d}\right)>0$ and $f_{2}(M)<0$ there must exist a unique $\operatorname{root}\left(\operatorname{say} T_{2}^{4}\right)$ to the equation $f_{2}(T)=0$ on $\left(T_{d}, M\right)$.

(c) If $F \leq\left(c I_{p}-\alpha s I_{e} /(\alpha+\theta)\right) e^{-(\alpha+\theta) M}, f_{3}(T)$ is increasing on $(M,+\infty)$. Otherwise, $f_{3}(T)$ is decreasing on $(M,+\infty)$.
Therefore, to solve the optimal order cycle time $T^{*}$ over $(0,+\infty)$, the possible interval which $F$ belongs to needs be considered; hence we should compare the size relations among values of $c I_{p}-\alpha s I_{e} /(\alpha+\theta)+\alpha s I_{e} M,\left(\theta s I_{e} /(\alpha+\right.$ $\theta)) e^{-(\alpha+\theta) M}$, and $\left(\theta s I_{e} /(\alpha+\theta)\right) e^{-(\alpha+\theta) T_{d}}$ with $\left(c I_{p}-\alpha s I_{e} /(\alpha+\right.$ $\theta)) e^{-(\alpha+\theta) M}$. Since $M \geq T_{d}$ and $c I_{p} \geq s I_{e}$, one will derive $\left(\theta s I_{e} /(\alpha+\theta)\right) e^{-(\alpha+\theta) M} \leq\left(\theta s I_{e} /(\alpha+\theta)\right) e^{-(\alpha+\theta) T_{d}}$ and $\left(\theta s I_{e} /(\alpha+\right.$ $\theta)) e^{-(\alpha+\theta) M} \leq\left(c I_{p}-\alpha s I_{e} /(\alpha+\theta)\right) e^{-(\alpha+\theta) M} \leq c I_{p}-\alpha s I_{e} /(\alpha+$ $\theta)+\alpha s I_{e} M$. So, there are three cases to occur: (i) $\left(\theta s I_{e} /(\alpha+\right.$ $\theta)) e^{-(\alpha+\theta) T_{d}} \leq\left(c I_{p}-\alpha s I_{e} /(\alpha+\theta)\right) e^{-(\alpha+\theta) M}$, (ii) $\left(c I_{p}-\alpha s I_{e} /(\alpha+\right.$ $\theta)) e^{-(\alpha+\theta) M}<\left(\theta s I_{e} /(\alpha+\theta)\right) e^{-(\alpha+\theta) T_{d}} \leq c I_{p}-\alpha s I_{e} /(\alpha+\theta)+$ $\alpha s I_{e} M$, and (iii) $\left(\theta s I_{e} /(\alpha+\theta)\right) e^{-(\alpha+\theta) T_{d}}>c I_{p}-\alpha s I_{e} /(\alpha+\theta)+$ $\alpha s I_{e} M$. Notice that once $F>\left(c I_{p}-\alpha s I_{e} /(\alpha+\theta)\right) e^{-(\alpha+\theta) M}$, the subfunction $\Pi_{3}(T)$ is always increasing over $(M,+\infty)$, so the profit function $\Pi(T)$ has no optimal solution over $(0,+\infty)$. Hence, we need only to study the two cases as below: (i) $\left(\theta s I_{e} /(\alpha+\theta)\right) e^{-(\alpha+\theta) T_{d}} \leq\left(c I_{p}-\alpha s I_{e} /(\alpha+\theta)\right) e^{-(\alpha+\theta) M}$ and (ii) $\left(\theta s I_{e} /(\alpha+\theta)\right) e^{-(\alpha+\theta) T_{d}}>\left(c I_{p}-\alpha s I_{e} /(\alpha+\theta)\right) e^{-(\alpha+\theta) M}$. According to these two cases and from some analysis, the proof of Theorems 4 and 5 would be obtained.

Proof of Theorem 4. If $M \geq T_{d}$ and $\left(\theta s I_{e} /(\alpha+\theta)\right) e^{-(\alpha+\theta) T_{d}} \leq$ $\left(c I_{p}-\alpha s I_{e} /(\alpha+\theta)\right) e^{-(\alpha+\theta) M}$, then we could obtain that $\left(\theta s I_{e} /(\alpha+\theta)\right) e^{-(\alpha+\theta) M} \leq\left(\theta s I_{e} /(\alpha+\theta)\right) e^{-(\alpha+\theta) T_{d}} \leq\left(c I_{p}-\right.$ $\left.\alpha s I_{e} /(\alpha+\theta)\right) e^{-(\alpha+\theta) M} \leq c I_{p}-\alpha s I_{e} /(\alpha+\theta)+\alpha s I_{e} M$. Hence, we have the following.

(1) When $F \leq\left(\theta s I_{e} /(\alpha+\theta)\right) e^{-(\alpha+\theta) M}$, since $f_{1}\left(T_{d}\right)>$ $f_{2}\left(T_{d}\right)$ and $f_{2}(T)$ is increasing on $\left(T_{d}, M\right)$ there are the following five possible cases to occur.

(A) If $f_{1}\left(T_{d}\right) \leq 0, f_{2}\left(T_{d}\right)<0$, and $f_{2}(M) \leq 0$, then $T_{1}^{0} \geq T_{d}$ and $T_{3}^{0} \geq M$. These yield that (i) $\Pi_{1}(T)$ is increasing on $\left(0, T_{d}\right)$; (ii) $\Pi_{2}(T)$ is increasing on $\left(T_{d}, M\right)$; (iii) $\Pi_{3}(T)$ is increasing on $\left(M, T_{3}^{0}\right)$ and decreasing on $\left(T_{3}^{0},+\infty\right)$. Combining (i)(iii) and $\Pi_{1}\left(T_{d}\right)<\Pi_{2}\left(T_{d}\right)$, we conclude that $\Pi\left(T^{*}\right)=\Pi_{3}\left(T_{3}^{0}\right)$; hence $T^{*}$ is $T_{3}^{0}$.

(B) If $f_{1}\left(T_{d}\right) \leq 0, f_{2}\left(T_{d}\right)<0$, and $f_{2}(M)>0$, then $T_{1}^{0} \geq T_{d}, T_{d}<T_{2}^{3}<M$, and $T_{3}^{0}<$ $M$. These yield that (i) $\Pi_{1}(T)$ is increasing on $\left(0, T_{d}\right)$; (ii) $\Pi_{2}(T)$ is increasing on $\left(T_{d}, T_{2}^{3}\right)$ and decreasing on $\left(T_{2}^{3}, M\right)$; (iii) $\Pi_{3}(T)$ is decreasing on $(M,+\infty)$. Combining (i)-(iii) and $\Pi_{1}\left(T_{d}\right)<$ $\Pi_{2}\left(T_{d}\right)$, we conclude that $\Pi\left(T^{*}\right)=\Pi_{2}\left(T_{2}^{3}\right)$; hence $T^{*}$ is $T_{2}^{3}$.

(C) If $f_{1}\left(T_{d}\right)>0, f_{2}\left(T_{d}\right)<0$, and $f_{2}(M)>0$, then $0<T_{1}^{0}<T_{d}, T_{d}<T_{2}^{3}<M$, and $T_{3}^{0}<M$. These yield that $(\mathrm{i}) \Pi_{1}(T)$ is increasing on $\left(0, T_{1}^{0}\right)$ and decreasing $\left(T_{1}^{0}, T_{d}\right)$; (ii) $\Pi_{2}(T)$ is increasing on $\left(T_{d}, T_{2}^{3}\right)$ and decreasing on $\left(T_{2}^{3}, M\right)$; (iii) $\Pi_{3}(T)$ is decreasing on $(M,+\infty)$. Combining (i)-(iii) and $\Pi_{1}\left(T_{d}\right)<\Pi_{2}\left(T_{d}\right)$, we conclude that $\Pi\left(T^{*}\right)=\max \left\{\Pi_{1}\left(T_{1}^{0}\right), \Pi_{2}\left(T_{2}^{3}\right)\right\}$. Hence $T^{*}$ is $T_{1}^{0}$ or $T_{2}^{3}$ associated with maximum profit. 
(D) If $f_{1}\left(T_{d}\right)>0, f_{2}\left(T_{d}\right)<0$, and $f_{2}(M) \leq 0$, then $0<T_{1}^{0}<T_{d}$ and $T_{3}^{0} \geq M$. These yield that (i) $\Pi_{1}(T)$ is increasing on $\left(0, T_{1}^{0}\right)$ and decreasing $\left(T_{1}^{0}, T_{d}\right)$; (ii) $\Pi_{2}(T)$ is increasing on $\left(T_{d}, M\right)$; (iii) $\Pi_{3}(T)$ is increasing on $\left(M, T_{3}^{0}\right)$ and decreasing on $\left(T_{3}^{0},+\infty\right)$. Combining (i)(iii) and $\Pi_{1}\left(T_{d}\right)<\Pi_{2}\left(T_{d}\right)$, we could conclude that $\Pi\left(T^{*}\right)=\max \left\{\Pi_{1}\left(T_{1}^{0}\right), \Pi_{3}\left(T_{3}^{0}\right)\right\}$. Hence $T^{*}$ is $T_{1}^{0}$ or $T_{3}^{0}$ associated with maximum profit.

(E) If $f_{1}\left(T_{d}\right)>0, f_{2}\left(T_{d}\right) \geq 0$, and $f_{2}(M)>0$, then $0<T_{1}^{0}<T_{d}$ and $T_{3}^{0}<M$. These yield that (i) $\Pi_{1}(T)$ is increasing on $\left(0, T_{1}^{0}\right)$ and decreasing on $\left(T_{1}^{0}, T_{d}\right)$; (ii) $\Pi_{2}(T)$ is decreasing on $\left(T_{d}, M\right)$; (iii) $\Pi_{3}(T)$ is decreasing on $(M,+\infty)$. Combining (i)-(iii) and $\Pi_{1}\left(T_{d}\right)<\Pi_{2}\left(T_{d}\right)$, we conclude that $\Pi\left(T^{*}\right)=\max \left\{\Pi_{1}\left(T_{1}^{0}\right), \Pi_{2}\left(T_{d}\right)\right\}$. Hence $T^{*}$ is $T_{1}^{0}$ or $T_{d}$ associated with maximum profit.

(2) When $\left(\theta s I_{e} /(\alpha+\theta)\right) e^{-(\alpha+\theta) M}<F \leq\left(\theta s I_{e} /(\alpha+\right.$ $\theta)) e^{-(\alpha+\theta) T_{d}}$, then $d f_{2}(T) / d T>0$ for $T \in\left(T_{d}, T^{\#}\right)$ and $d f_{2}(T) / d T<0$ for $T \in\left(T^{\#}, M\right)$.

(A) While $f_{2}\left(T^{\#}\right)>0$, we have the following.

(a) If $f_{1}\left(T_{d}\right) \leq 0, f_{2}\left(T_{d}\right)<0$, and $f_{2}(M) \leq 0$, then $T_{1}^{0} \geq T_{d}, T_{d}<T_{2}^{1}<T^{\#}, T^{\#}<$ $T_{2}^{2} \leq M$, and $T_{3}^{0} \geq M$. These yield that (i) $\Pi_{1}(T)$ is increasing on $\left(0, T_{d}\right)$; (ii) $\Pi_{2}(T)$ is increasing on $\left(T_{d}, T_{2}^{1}\right)$, decreasing on $\left(T_{2}^{1}, T_{2}^{2}\right)$, and increasing on $\left(T_{2}^{2}, M\right)$; (iii) $\Pi_{3}(T)$ is increasing on $\left(M, T_{3}^{0}\right)$ and decreasing on $\left(T_{3}^{0},+\infty\right)$. Combining (i)(iii) and $\Pi_{1}\left(T_{d}\right)<\Pi_{2}\left(T_{d}\right)$, we conclude that $\Pi\left(T^{*}\right)=\max \left\{\Pi_{2}\left(T_{2}^{1}\right), \Pi_{3}\left(T_{3}^{0}\right)\right\}$. Hence $T^{*}$ is $T_{2}^{1}$ or $T_{3}^{0}$ associated with maximum profit.

(b) If $f_{1}\left(T_{d}\right) \leq 0, f_{2}\left(T_{d}\right)<0$, and $f_{2}(M)>0$, then $T_{1}^{0} \geq T_{d}, T_{d}<T_{2}^{1}<T^{\#}$, and $T_{3}^{0}<M$. These yield that (i) $\Pi_{1}(T)$ is increasing on $\left(0, T_{d}\right)$; (ii) $\Pi_{2}(T)$ is increasing on $\left(T_{d}, T_{2}^{1}\right)$ and decreasing on $\left(T_{2}^{1}, M\right)$; (iii) $\Pi_{3}(T)$ is decreasing on $(M,+\infty)$. Combining (i)(iii) and $\Pi_{1}\left(T_{d}\right)<\Pi_{2}\left(T_{d}\right)$, we conclude that $\Pi\left(T^{*}\right)=\Pi_{2}\left(T_{2}^{1}\right)$. Hence $T^{*}$ is $T_{2}^{1}$.

(c) If $f_{1}\left(T_{d}\right)>0, f_{2}\left(T_{d}\right)<0$, and $f_{2}(M) \leq 0$, then $0<T_{1}^{0}<T_{d}, T_{d}<T_{2}^{1}<T^{\#}$, $T^{\#}<T_{2}^{2} \leq M$, and $T_{3}^{0} \geq M$. These yield that (i) $\Pi_{1}(T)$ is increasing on $\left(0, T_{1}^{0}\right)$ and decreasing $\left(T_{1}^{0}, T_{d}\right)$; (ii) $\Pi_{2}(T)$ is increasing on $\left(T_{d}, T_{2}^{1}\right)$, decreasing on $\left(T_{2}^{1}, T_{2}^{2}\right)$, and increasing on $\left(T_{2}^{2}, M\right)$; (iii) $\Pi_{3}(T)$ is increasing on $\left(M, T_{3}^{0}\right)$ and decreasing on $\left(T_{3}^{0},+\infty\right)$. Combining (i)-(iii) and $\Pi_{1}\left(T_{d}\right)<\Pi_{2}\left(T_{d}\right)$, we conclude that $\Pi\left(T^{*}\right)=\max \left\{\Pi_{1}\left(T_{1}^{0}\right), \Pi_{2}\left(T_{2}^{1}\right), \Pi_{3}\left(T_{3}^{0}\right)\right\}$. Hence $T^{*}$ is $T_{1}^{0}, T_{2}^{1}$, or $T_{3}^{0}$ associated with maximum profit. (d) If $f_{1}\left(T_{d}\right)>0, f_{2}\left(T_{d}\right)<0$, and $f_{2}(M)>0$, then $0<T_{1}^{0}<T_{d}, T_{d}<T_{2}^{1}<T^{\#}$, and $T_{3}^{0}<M$. These yield that (i) $\Pi_{1}(T)$ is increasing on $\left(0, T_{1}^{0}\right)$ and decreasing $\left(T_{1}^{0}, T_{d}\right)$; (ii) $\Pi_{2}(T)$ is increasing on $\left(T_{d}, T_{2}^{1}\right)$ and decreasing on $\left(T_{2}^{1}, M\right)$; (iii) $\Pi_{3}(T)$ is decreasing on $(M,+\infty)$. Combining (i)(iii) and $\Pi_{1}\left(T_{d}\right)<\Pi_{2}\left(T_{d}\right)$, we conclude that $\Pi\left(T^{*}\right)=\max \left\{\Pi_{1}\left(T_{1}^{0}\right), \Pi_{2}\left(T_{2}^{1}\right)\right\}$. Hence $T^{*}$ is $T_{1}^{0}$ or $T_{2}^{1}$ associated with maximum profit.

(e) If $f_{1}\left(T_{d}\right)>0, f_{2}\left(T_{d}\right) \geq 0$, and $f_{2}(M) \leq 0$, then $0<T_{1}^{0}<T_{d}, T^{\#}<T_{2}^{2} \leq M$, and $T_{3}^{0} \geq M$. These yield that (i) $\Pi_{1}(T)$ is increasing on $\left(0, T_{1}^{0}\right)$ and decreasing $\left(T_{1}^{0}, T_{d}\right)$; (ii) $\Pi_{2}(T)$ is decreasing on $\left(T_{d}, T_{2}^{2}\right)$ and increasing on $\left(T_{2}^{2}, M\right)$; (iii) $\Pi_{3}(T)$ is increasing on $\left(M, T_{3}^{0}\right)$ and decreasing on $\left(T_{3}^{0},+\infty\right)$. Combining (i)-(iii) and $\Pi_{1}\left(T_{d}\right)<\Pi_{2}\left(T_{d}\right)$, we conclude that $\Pi\left(T^{*}\right)=\max \left\{\Pi_{1}\left(T_{1}^{0}\right), \Pi_{2}\left(T_{d}\right), \Pi_{3}\left(T_{3}^{0}\right)\right\}$. Hence $T^{*}$ is $T_{1}^{0}, T_{d}$, or $T_{3}^{0}$ associated with maximum profit.

(f) If $f_{1}\left(T_{d}\right)>0, f_{2}\left(T_{d}\right) \geq 0$, and $f_{2}(M)>$ 0 , then $0<T_{1}^{0}<T_{d}$, and $T_{3}^{0}<M$. These yield that (i) $\Pi_{1}(T)$ is increasing on $\left(0, T_{1}^{0}\right)$ and decreasing $\left(T_{1}^{0}, T_{d}\right)$; (ii) $\Pi_{2}(T)$ is decreasing on $\left(T_{d}, M\right)$; (iii) $\Pi_{3}(T)$ is decreasing on $(M,+\infty)$. Combining (i)(iii) and $\Pi_{1}\left(T_{d}\right)<\Pi_{2}\left(T_{d}\right)$, we conclude that $\Pi\left(T^{*}\right)=\max \left\{\Pi_{1}\left(T_{1}^{0}\right), \Pi_{2}\left(T_{d}\right)\right\}$. Hence $T^{*}$ is $T_{1}^{0}$ or $T_{d}$ associated with maximum profit.

(B) While $f_{2}\left(T^{\#}\right) \leq 0$, then $f_{2}\left(T_{d}\right)<0$ and $f_{2}(M)<$ 0 .

(a) If $f_{1}\left(T_{d}\right) \leq 0, f_{2}\left(T_{d}\right)<0$, and $f_{2}(M)<0$, then $T_{1}^{0} \geq T_{d}$ and $T_{3}^{0}>M$. These yield that (i) $\Pi_{1}(T)$ is increasing on $\left(0, T_{d}\right)$; (ii) $\Pi_{2}(T)$ is increasing on $\left(T_{d}, M\right)$; (iii) $\Pi_{3}(T)$ is increasing on $\left(M, T_{3}^{0}\right)$ and decreasing on $\left(T_{3}^{0},+\infty\right)$. Combining (i)-(iii) and $\Pi_{1}\left(T_{d}\right)<\Pi_{2}\left(T_{d}\right)$, we conclude that $\Pi\left(T^{*}\right)=\Pi_{3}\left(T_{3}^{0}\right)$. Hence $T^{*}$ is $T_{3}^{0}$.

(b) If $f_{1}\left(T_{d}\right)>0, f_{2}\left(T_{d}\right)<0$, and $f_{2}(M)<0$, then $0<T_{1}^{0}<T_{d}$ and $T_{3}^{0}>M$. These yield that (i) $\Pi_{1}(T)$ is increasing on $\left(0, T_{1}^{0}\right)$ and decreasing on $\left(T_{1}^{0}, T_{d}\right)$; (ii) $\Pi_{2}(T)$ is increasing on $\left(T_{d}, M\right)$; (iii) $\Pi_{3}(T)$ is increasing on $\left(M, T_{3}^{0}\right)$ and decreasing on $\left(T_{3}^{0},+\infty\right)$. Combining (i)(iii) and $\Pi_{1}\left(T_{d}\right)<\Pi_{2}\left(T_{d}\right)$, we conclude that $\Pi\left(T^{*}\right)=\max \left\{\Pi_{1}\left(T_{1}^{0}\right), \Pi_{3}\left(T_{3}^{0}\right)\right\}$. Hence $T^{*}$ is $T_{1}^{0}$ or $T_{3}^{0}$ associated with maximum profit. 
(3) When $\left(\theta s I_{e} /(\alpha+\theta)\right) e^{-(\alpha+\theta) T_{d}}<F \leq\left(c I_{p}-\alpha s I_{e} /(\alpha+\right.$ $\theta)) e^{-(\alpha+\theta) M}$, since $f_{1}\left(T_{d}\right)>f_{2}\left(T_{d}\right)$ and $f_{2}(T)$ is decreasing on $\left(T_{d}, M\right)$ there are the following four possible cases to occur.

(A) If $f_{1}\left(T_{d}\right) \leq 0, f_{2}\left(T_{d}\right)<0$, and $f_{2}(M)<0$, then $T_{1}^{0} \geq T_{d}$ and $T_{3}^{0}>M$. These yield that (i) $\Pi_{1}(T)$ is increasing on $\left(0, T_{d}\right)$; (ii) $\Pi_{2}(T)$ is increasing on $\left(T_{d}, M\right)$; (iii) $\Pi_{3}(T)$ is increasing on $\left(M, T_{3}^{0}\right)$ and decreasing on $\left(T_{3}^{0},+\infty\right)$. Combining (i)(iii) and $\Pi_{1}\left(T_{d}\right)<\Pi_{2}\left(T_{d}\right)$, we conclude that $\Pi\left(T^{*}\right)=\Pi_{3}\left(T_{3}^{0}\right)$. Hence $T^{*}$ is $T_{3}^{0}$.

(B) If $f_{1}\left(T_{d}\right)>0, f_{2}\left(T_{d}\right)<0$, and $f_{2}(M)<0$, then $0<T_{1}^{0}<T_{d}$ and $T_{3}^{0}>M$. These yield that (i) $\Pi_{1}(T)$ is increasing on $\left(0, T_{1}^{0}\right)$ and decreasing on $\left(T_{1}^{0}, T_{d}\right)$; (ii) $\Pi_{2}(T)$ is increasing on $\left(T_{d}, M\right)$; (iii) $\Pi_{3}(T)$ is increasing on $\left(M, T_{3}^{0}\right)$ and decreasing on $\left(T_{3}^{0},+\infty\right)$. Combining (i)(iii) and $\Pi_{1}\left(T_{d}\right)<\Pi_{2}\left(T_{d}\right)$, we conclude that $\Pi\left(T^{*}\right)=\max \left\{\Pi_{1}\left(T_{1}^{0}\right), \Pi_{3}\left(T_{3}^{0}\right)\right\}$. Hence $T^{*}$ is $T_{1}^{0}$ or $T_{3}^{0}$ associated with maximum profit.

(C) If $f_{1}\left(T_{d}\right)>0, f_{2}\left(T_{d}\right) \geq 0$, and $f_{2}(M)<0$, then $0<T_{1}^{0}<T_{d}, T_{d} \leq T_{2}^{4}<M$ and $T_{3}^{0}>M$. These yield that (i) $\Pi_{1}(T)$ is increasing on $\left(0, T_{1}^{0}\right)$ and decreasing on $\left(T_{1}^{0}, T_{d}\right)$; (ii) $\Pi_{2}(T)$ is decreasing on $\left(T_{d}, T_{2}^{4}\right)$ and increasing on $\left(T_{2}^{4}, M\right)$; (iii) $\Pi_{3}(T)$ is increasing on $\left(M, T_{3}^{0}\right)$ and decreasing on $\left(T_{3}^{0},+\infty\right)$. Combining (i)(iii) and $\Pi_{1}\left(T_{d}\right)<\Pi_{2}\left(T_{d}\right)$, we conclude that $\Pi\left(T^{*}\right)=\max \left\{\Pi_{1}\left(T_{1}^{0}\right), \Pi_{2}\left(T_{d}\right), \Pi_{3}\left(T_{3}^{0}\right)\right\}$. Hence $T^{*}$ is $T_{1}^{0}, T_{d}$, or $T_{3}^{0}$ associated with maximum profit.

(D) If $f_{1}\left(T_{d}\right)>0, f_{2}\left(T_{d}\right) \geq 0$, and $f_{2}(M) \geq 0$, then $0<T_{1}^{0}<T_{d}$ and $T_{3}^{0} \leq M$. These yield that (i) $\Pi_{1}(T)$ is increasing on $\left(0, T_{1}^{0}\right)$ and decreasing on $\left(T_{1}^{0}, T_{d}\right)$; (ii) $\Pi_{2}(T)$ is decreasing on $\left(T_{d}, M\right)$; (iii) $\Pi_{3}(T)$ is decreasing on $(M,+\infty)$. Combining (i)-(iii) and $\Pi_{1}\left(T_{d}\right)<\Pi_{2}\left(T_{d}\right)$, we conclude that $\Pi\left(T^{*}\right)=\max \left\{\Pi_{1}\left(T_{1}^{0}\right), \Pi_{2}\left(T_{d}\right)\right\}$. Hence $T^{*}$ is $T_{1}^{0}$ or $T_{d}$ associated with maximum profit.

(4) When $F>\left(c I_{p}-\alpha s I_{e} /(\alpha+\theta)\right) e^{-(\alpha+\theta) M}$, because on the interval of $(M,+\infty)$ the average profit function $\Pi(T)$ is always increasing, the optimal solution $T^{*}$ is $+\infty$ evidently.

This completes the proof of Theorem 4.

Proof of Theorem 5. If $\left(\theta s I_{e} /(\alpha+\theta)\right) e^{-(\alpha+\theta) T_{d}}>\left(c I_{p}-\alpha s I_{e} /(\alpha+\right.$ $\theta)) e^{-(\alpha+\theta) M}$, then one has $\left(\theta s I_{e} /(\alpha+\theta)\right) e^{-(\alpha+\theta) M} \leq\left(c I_{p}-\right.$ $\left.\alpha s I_{e} /(\alpha+\theta)\right) e^{-(\alpha+\theta) M}<\left(\theta s I_{e} /(\alpha+\theta)\right) e^{-(\alpha+\theta) T_{d}} \leq c I_{p}-$ $\alpha s I_{e} /(\alpha+\theta)+\alpha s I_{e} M$ or $\left(\theta s I_{e} /(\alpha+\theta)\right) e^{-(\alpha+\theta) M} \leq\left(c I_{p}-\right.$ $\left.\alpha s I_{e} /(\alpha+\theta)\right) e^{-(\alpha+\theta) M} \leq c I_{p}-\alpha s I_{e} /(\alpha+\theta)+\alpha s I_{e} M \leq$ $\left(\theta s I_{e} /(\alpha+\theta)\right) e^{-(\alpha+\theta) T_{d}}$. Since $\Pi(T)$ has no optimal solution when $F>\left(c I_{p}-\alpha s I_{e} /(\alpha+\theta)\right) e^{-(\alpha+\theta) M}$, so there are three possible situations to occur as below.
(1) When $F \leq\left(\theta s I_{e} /(\alpha+\theta)\right) e^{-(\alpha+\theta) M}$, it is obvious that the results are the same as (1) in Theorem 4.

(2) When $\left(\theta s I_{e} /(\alpha+\theta)\right) e^{-(\alpha+\theta) M}<F \leq\left(c I_{p}-\right.$ $\left.\alpha s I_{e} /(\alpha+\theta)\right) e^{-(\alpha+\theta) M}$, the results are the same as (2) in Theorem 4.

(3) When $F>\left(c I_{p}-\alpha s I_{e} /(\alpha+\theta)\right) e^{-(\alpha+\theta) M}$, because on the interval of $(M,+\infty)$ the average profit function $\Pi(T)$ is always increasing, the optimal solution $T^{*}$ is $+\infty$ evidently.

This completes the proof of Theorem 5 .

\section{F. Proof of Theorem 6}

According to the anterior analysis in Section 4, we could get the below results.

(a) If $F<c I_{p}-\alpha s I_{e} /(\alpha+\theta)+\alpha s I_{e} M, f_{1}(T)$ is increasing on $\left(0, T_{d}\right)$. Otherwise, $f_{1}(T)$ is decreasing on $\left(0, T_{d}\right)$.

(b) If $F \leq\left(c I_{p}-\alpha s I_{e} /(\alpha+\theta)\right) e^{-(\alpha+\theta) M}$, then $f_{3}(T)$ is increasing on $\left(T_{d},+\infty\right)$. Otherwise, $f_{3}(T)$ is strictly decreasing on $\left(T_{d},+\infty\right)$.

Similarly, in order to find the system's optimal cycle time $T^{*}$, the possible interval which $F$ belongs to needs be considered if $M<T_{d}$; hence we should compare the size relations between $c I_{p}-\alpha s I_{e} /(\alpha+\theta)+\alpha s I_{e} M$ and $\left(c I_{p}-\right.$ $\left.\alpha s I_{e} /(\alpha+\theta)\right) e^{-(\alpha+\theta) M}$. If $c I_{p} \geq s I_{e}$, then one has $\left(c I_{p}-\alpha s I_{e} /(\alpha+\right.$ $\theta)) e^{-(\alpha+\theta) M} \leq c I_{p}-\alpha s I_{e} /(\alpha+\theta)+\alpha s I_{e} M$.

(1) When $F \leq\left(c I_{p}-\alpha s I_{e} /(\alpha+\theta)\right) e^{-(\alpha+\theta) M}$, we have the following.

(A) If $f_{1}\left(T_{d}\right) \leq 0$ and $f_{3}\left(T_{d}\right)<0$, then $T_{1}^{0} \geq T_{d}$ and $T_{3}^{0}>T_{d}$. These yield that (i) $\Pi_{1}(T)$ is increasing on $\left(0, T_{d}\right)$; (ii) $\Pi_{3}(T)$ is increasing on $\left(T_{d}, T_{3}^{0}\right)$ and decreasing on $\left(T_{3}^{0},+\infty\right)$. Combining (i)(ii) and $\Pi_{1}\left(T_{d}\right)<\Pi_{3}\left(T_{d}\right)$, we conclude that $\Pi\left(T^{*}\right)=\Pi_{3}\left(T_{3}^{0}\right)$. Hence $T^{*}$ is $T_{3}^{0}$.

(B) If $f_{1}\left(T_{d}\right)>0$ and $f_{3}\left(T_{d}\right) \geq 0$, then $0<$ $T_{1}^{0}<T_{d}$ and $T_{3}^{0} \leq T_{d}$. These yield that (i) $\Pi_{1}(T)$ is increasing on $\left(0, T_{1}^{0}\right)$ and decreasing on $\left(T_{1}^{0}, T_{d}\right)$; (ii) $\Pi_{3}(\mathrm{~T})$ is decreasing on $\left(T_{d},+\infty\right)$. Combining (i)-(ii) and $\Pi_{1}\left(T_{d}\right)<\Pi_{3}\left(T_{d}\right)$, we conclude that $\Pi\left(T^{*}\right)=\max \left\{\Pi_{1}\left(T_{1}^{0}\right), \Pi_{3}\left(T_{d}\right)\right\}$. Hence $T^{*}$ is $T_{1}^{0}$ or $T_{d}$ associated with the maximum profit.

(C) If $f_{1}\left(T_{d}\right)>0$ and $f_{3}\left(T_{d}\right)<0$, then $0<$ $T_{1}^{0}<T_{d}$ and $T_{3}^{0}>T_{d}$. These yield that (i) $\Pi_{1}(T)$ is increasing on $\left(0, T_{1}^{0}\right)$ and decreasing on $\left(T_{1}^{0}, T_{d}\right)$; (ii) $\Pi_{3}(T)$ is increasing on $\left(T_{d}, T_{3}^{0}\right)$ and decreasing on $\left(T_{3}^{0},+\infty\right)$. Combining (i)-(ii) and $\Pi_{1}\left(T_{d}\right)<\Pi_{3}\left(T_{d}\right)$, we can conclude that $\Pi\left(T^{*}\right)=\max \left\{\Pi_{1}\left(T_{1}^{0}\right), \Pi_{3}\left(T_{3}^{0}\right)\right\}$. Hence $T^{*}$ is $T_{1}^{0}$ or $T_{3}^{0}$ associated with the maximum profit. 
(2) When $F>\left(c I_{p}-\alpha s I_{e} /(\alpha+\theta)\right) e^{-(\alpha+\theta) M}$, because on the interval of $(M,+\infty)$ the average profit function $\Pi(T)$ is always increasing, the optimal solution $T^{*}$ is $+\infty$ evidently.

This completes the proof of Theorem 6 .

\section{Conflict of Interests}

The authors declare that there is no conflict of interests regarding the publication of this paper.

\section{Acknowledgments}

This work was supported in part by the National Natural Science Foundation of China Project under project Grant nos. 71101002, 71072165, 71201044, 71131003, and 71231004. The authors have benefited substantially from the insightful comments of the editor and anonymous referees, which were instrumental for elevating the quality of this work.

\section{References}

[1] T. M. Whitin, The Theory of Inventory Management, Princeton University Press, Princeton, NJ, USA, 1957.

[2] R. I. Levin, C. P. McLaughlin, R. P. Lamone, and J. F. Kottas, Production/Operations Management: Contemporary Policy for Managing Operating Systems, McGraw-Hill, New York, NY, USA, 1972.

[3] E. A. Silver and R. Peterson, Decision Systems for Inventory Management and Production Planning, Wiley, New York, NY, USA, 1985.

[4] R. Gupta and P. Vrat, "Inventory model for stock-dependent consumption rate," Opsearch, vol. 23, no. 1, pp. 19-24, 1986.

[5] G. Padmanabhan and P. Vrat, "An EOQ model for items with stock dependent consumption rate and exponential decay," Engineering Costs and Production Economics, vol. 18, no. 3, pp. 241-246, 1990.

[6] B. C. Giri, S. Pal, A. Goswami, and K. S. Chaudhuri, "An inventory model for deteriorating items with stock-dependent demand rate," European Journal of Operational Research, vol. 95, no. 3, pp. 604-610, 1996.

[7] R. C. Baker and T. L. Urban, "A deterministic inventory system with an inventory level-dependent demand rate," Journal of the Operational Research Society, vol. 39, no. 9, pp. 823-831, 1988.

[8] B. N. Mandal and S. Phaujdar, "An inventory model for deteriorating items and stock-dependent consumption rate," Journal of the Operational Research Society, vol. 40, no. 5, pp. 483-488, 1989.

[9] S. Pal, A. Goswami, and K. S. Chaudhuri, "A deterministic inventory model for deteriorating items with stock-dependent demand rate," International Journal of Production Economics, vol. 32, no. 3, pp. 291-299, 1993.

[10] G. Padmanabhan and P. Vrat, "EOQ models for perishable items under stock dependent selling rate," European Journal of Operational Research, vol. 86, no. 2, pp. 281-292, 1995.

[11] K.-J. Chung, P. Chu, and S.-P. Lan, "A note on EOQ models for deteriorating items under stock dependent selling rate," European Journal of Operational Research, vol. 124, no. 3, pp. 550-559, 2000.
[12] Y.-W. Zhou and S.-L. Yang, "An optimal replenishment policy for items with inventory-level-dependent demand and fixed lifetime under the LIFO policy," Journal of the Operational Research Society, vol. 54, no. 6, pp. 585-593, 2003.

[13] Z. T. Balkhi and L. Benkherouf, "On an inventory model for deteriorating items with stock dependent and time-varying demand rates," Computers \& Operations Research, vol. 31, no. 2, pp. 223-240, 2004.

[14] C.-Y. Dye and L.-Y. Ouyang, "An EOQ model for perishable items under stock-dependent selling rate and time-dependent partial backlogging," European Journal of Operational Research, vol. 163, no. 3, pp. 776-783, 2005.

[15] Y.-W. Zhou and S.-L. Yang, "A two-warehouse inventory model for items with stock-level-dependent demand rate," International Journal of Production Economics, vol. 95, no. 2, pp. 215228, 2005.

[16] K.-S. Wu, L.-Y. Ouyang, and C.-T. Yang, "An optimal replenishment policy for non-instantaneous deteriorating items with stock-dependent demand and partial backlogging," International Journal of Production Economics, vol. 101, no. 2, pp. 369384, 2006.

[17] H. K. Alfares, "Inventory model with stock-level dependent demand rate and variable holding cost," International Journal of Production Economics, vol. 108, no. 1-2, pp. 259-265, 2007.

[18] S. K. Goyal, "Economic order quantity under conditions of permissible delay in payments," Journal of the Operational Research Society, vol. 36, no. 4, pp. 335-338, 1985.

[19] S. P. Aggarwal and C. K. Jaggi, "Ordering policies of deteriorating items under permissible delay in payments," Journal of the Operational Research Society, vol. 46, no. 5, pp. 658-662, 1995.

[20] A. M. M. Jamal, B. R. Sarker, and S. Wang, "An ordering policy for deteriorating items with allowable shortage and permissible delay in payment," Journal of the Operational Research Society, vol. 48, no. 8, pp. 826-833, 1997.

[21] B. R. Sarker, A. M. M. Jamal, and S. Wang, "Supply chain models for perishable products under inflation and permissible delay in payment," Computers \& Operations Research, vol. 27, no. 1, pp. $59-75,2000$.

[22] J.-T. Teng, "On the economic order quantity under conditions of permissible delay in payments," Journal of the Operational Research Society, vol. 53, no. 8, pp. 915-918, 2002.

[23] Y.-F. Huang, "Optimal retailer's ordering policies in the EOQ model under trade credit financing," Journal of the Operational Research Society, vol. 54, no. 9, pp. 1011-1015, 2003.

[24] C.-T. Chang, L.-Y. Ouyang, and J.-T. Teng, "An EOQ model for deteriorating items under supplier credits linked to ordering quantity," Applied Mathematical Modelling, vol. 27, no. 12, pp. 983-996, 2003.

[25] C.-T. Chang, "An EOQ model with deteriorating items under inflation when supplier credits linked to order quantity," International Journal of Production Economics, vol. 88, no. 3, pp. 307316, 2004.

[26] K.-J. Chung and J.-J. Liao, "Lot-sizing decisions under trade credit depending on the ordering quantity," Computers \& Operations Research, vol. 31, no. 6, pp. 909-928, 2004.

[27] J.-T. Teng, C.-T. Chang, and S. K. Goyal, "Optimal pricing and ordering policy under permissible delay in payments," International Journal of Production Economics, vol. 97, no. 2, pp. 121-129, 2005.

[28] J.-J. Liao, "A note on an EOQ model for deteriorating items under supplier credit linked to ordering quantity," Applied Mathematical Modelling, vol. 31, no. 8, pp. 1690-1699, 2007. 
[29] J.-T. Teng and S. K. Goyal, "Optimal ordering policies for a retailer in a supply chain with up-stream and down-stream trade credits," Journal of the Operational Research Society, vol. 58, no. 9, pp. 1252-1255, 2007.

[30] S.-C. Chen, L. E. Cárdenas-Barrón, and J.-T. Teng, "Retailer's economic order quantity when the supplier offers conditionally permissible delay in payments link to order quantity," International Journal of Production Economics, vol. 155, pp. 284-291, 2013.

[31] C.-T. Chang, M.-C. Cheng, and L.-Y. Ouyang, "Optimal pricing and ordering policies for non-instantaneously deteriorating items under order-size-dependent delay in payments," Applied Mathematical Modelling, 2014. 


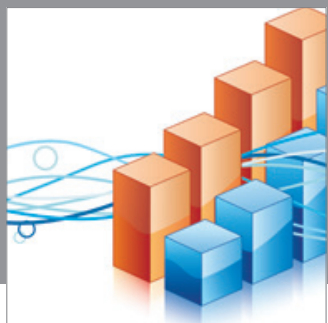

Advances in

Operations Research

mansans

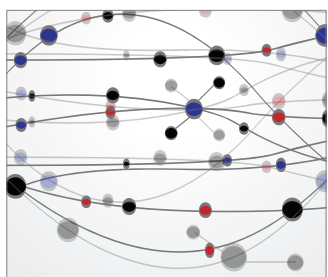

The Scientific World Journal
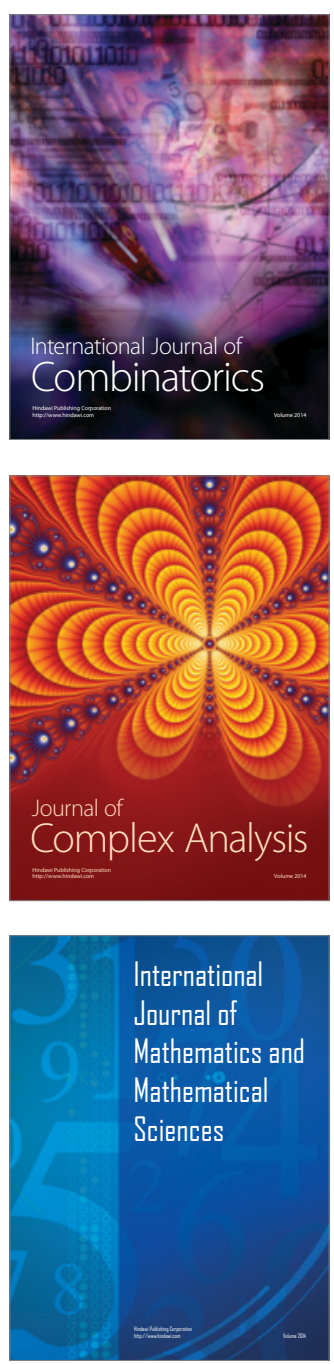
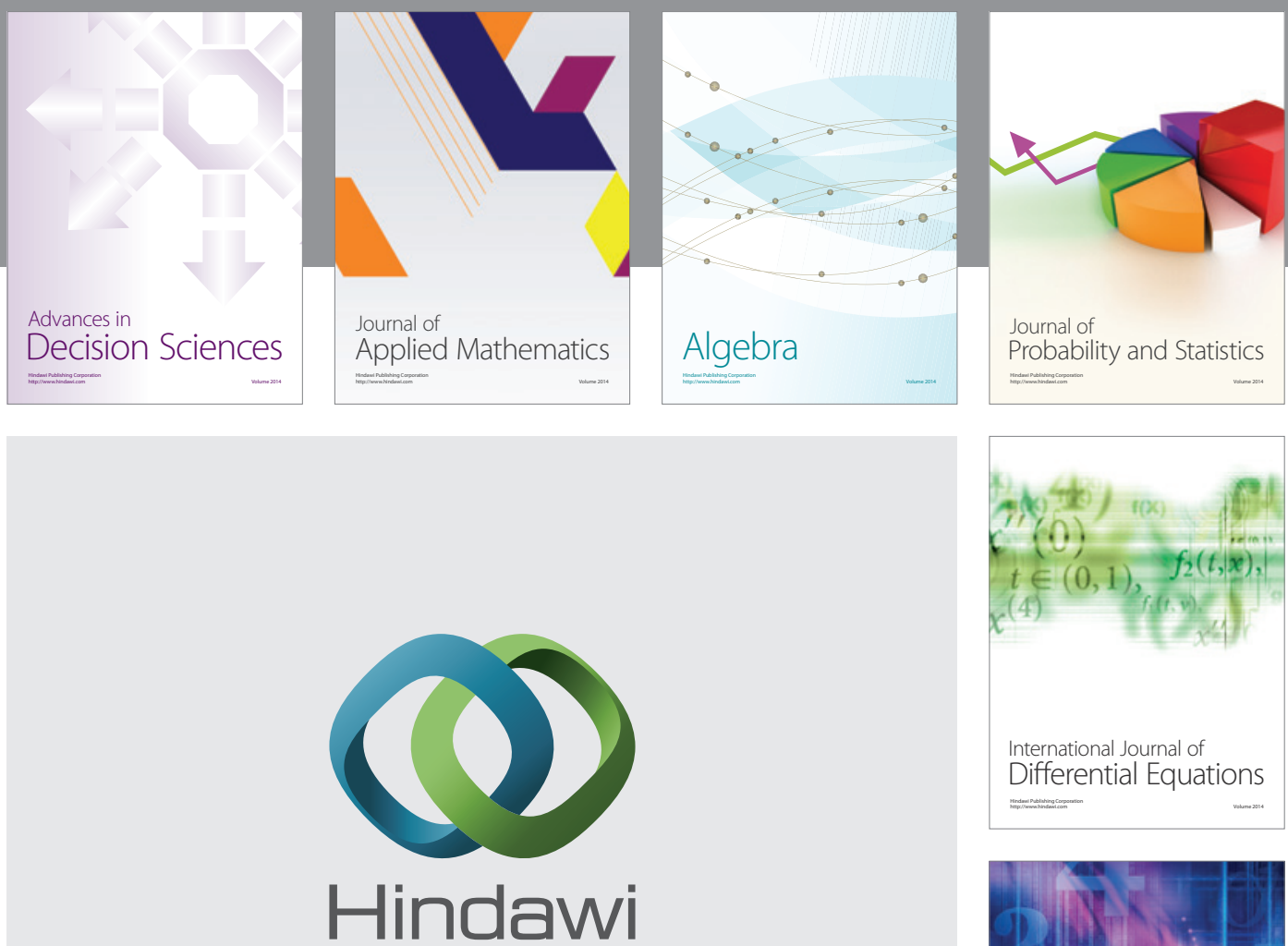

Submit your manuscripts at http://www.hindawi.com
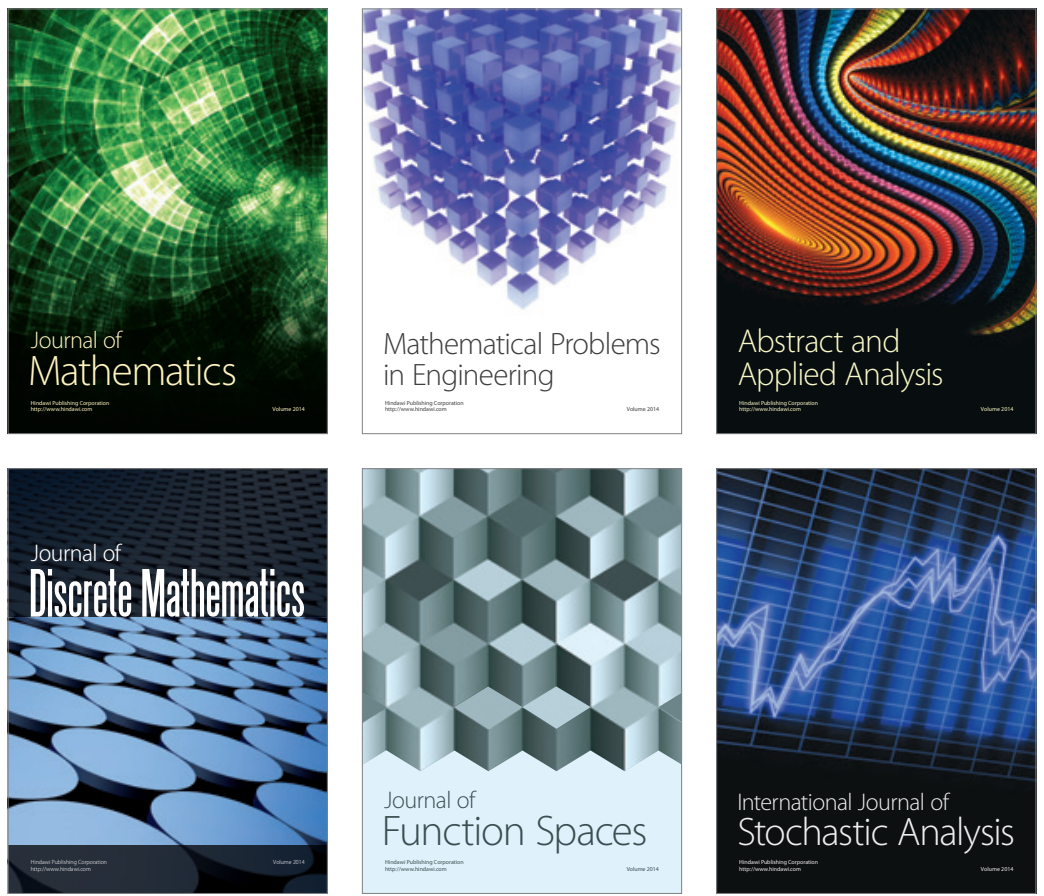

Journal of

Function Spaces

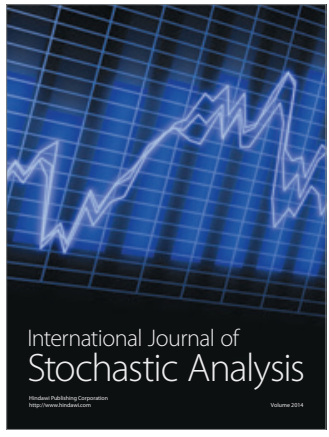

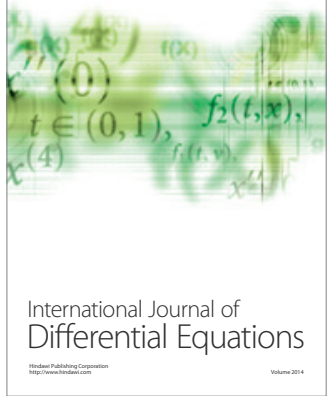
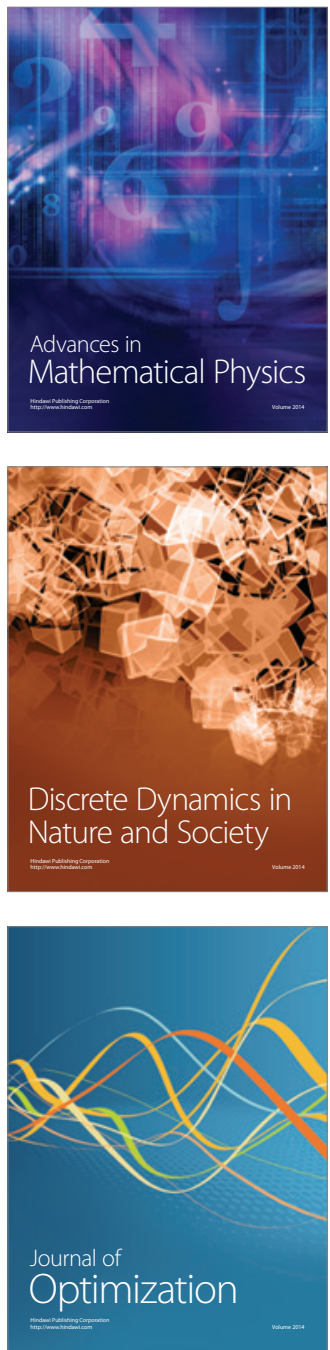